\title{
SPES3 Facility RELAP5 Sensitivity Analyses on the Containment System for Design Review
}

\author{
Andrea Achilli, ${ }^{1}$ Cinzia Congiu, ${ }^{1}$ Roberta Ferri, ${ }^{1}$ Fosco Bianchi, ${ }^{2}$ Paride Meloni, ${ }^{2}$ \\ Davor Grgić, ${ }^{3}$ and Milorad Dzodzo ${ }^{4}$
}

\author{
${ }^{1}$ SIET S.p.A., UdP, Via Nino Bixio 27/c, 29121 Piacenza, Italy \\ ${ }^{2}$ ENEA, UTFISSM, Via Martiri di Monte Sole 4, 40129 Bologna, Italy \\ ${ }^{3}$ FER, University of Zagreb, Unska 3, 10000 Zagreb, Croatia \\ ${ }^{4}$ Research and Technology Unit, Westinghouse Electric Company LLC, Cranberry Township, PA 16066, USA
}

Correspondence should be addressed to Roberta Ferri, ferri@siet.it

Received 11 March 2011; Accepted 27 July 2011

Academic Editor: Alessandro Del Nevo

Copyright () 2012 Andrea Achilli et al. This is an open access article distributed under the Creative Commons Attribution License, which permits unrestricted use, distribution, and reproduction in any medium, provided the original work is properly cited.

\begin{abstract}
An Italian MSE R\&D programme on Nuclear Fission is funding, through ENEA, the design and testing of SPES3 facility at SIET, for IRIS reactor simulation. IRIS is a modular, medium size, advanced, integral PWR, developed by an international consortium of utilities, industries, research centres and universities. SPES3 simulates the primary, secondary and containment systems of IRIS, with 1:100 volume scale, full elevation and prototypical thermal-hydraulic conditions. The RELAP5 code was extensively used in support to the design of the facility to identify criticalities and weak points in the reactor simulation. FER, at Zagreb University, performed the IRIS reactor analyses with the RELAP5 and GOTHIC coupled codes. The comparison between IRIS and SPES3 simulation results led to a simulation-design feedback process with step-by-step modifications of the facility design, up to the final configuration. For this, a series of sensitivity cases was run to investigate specific aspects affecting the trend of the main parameters of the plant, as the containment pressure and EHRS removed power, to limit fuel clad temperature excursions during accidental transients. This paper summarizes the sensitivity analyses on the containment system that allowed to review the SPES3 facility design and confirm its capability to appropriately simulate the IRIS plant.
\end{abstract}

\section{Introduction}

The IRIS reactor, with its integral design, is an advanced engineering solution of the latest LWR technology. Mediumsized, safe, modular, and economic, it provides a viable bridge to generation IV and satisfies the GNEP requirements for grid-appropriate NPPs [1-3].

In the frame of an R\&D program on nuclear fission, funded by the Italian Ministry of Economic Development, ENEA, as member of the IRIS consortium, is supporting the design, construction, and testing of the SPES3 ITF at SIET laboratories [4-6].

The SPES3 design was carried out following the subsequent steps: (a) definition of a preliminary facility design, based on specified system geometry; (b) setup of the RELAP5 facility model and DBA simulation; (c) comparison of SPES3 and IRIS results against the same transient; (d) identification of the main differences and understanding of related reasons; (e) FSA application to selected thermofluid-dynamic parameters in order to assess and quantify the discrepancies; (f) updating of the SPES3 design to match the IRIS behaviour; (g) final result comparison; (h) final FSA application and assessment of acceptability criteria for considering SPES3 correctly simulating IRIS.

The above-mentioned process allowed to verify the SBLOCA PIRT objectives for the IRIS reactor, as defined by a group of international experts [7]. The Phenomena Identification and Ranking Table put in evidence the thermalhydraulic phenomena playing an important role in operation of IRIS safety systems. Two figures of merit were considered fundamental for the accident sequence control: containment pressure and reactor vessel mass inventory. Sufficient water in the vessel allows to remove stored energy, and decay heat without fuel clad temperature excursions and adequate heat 


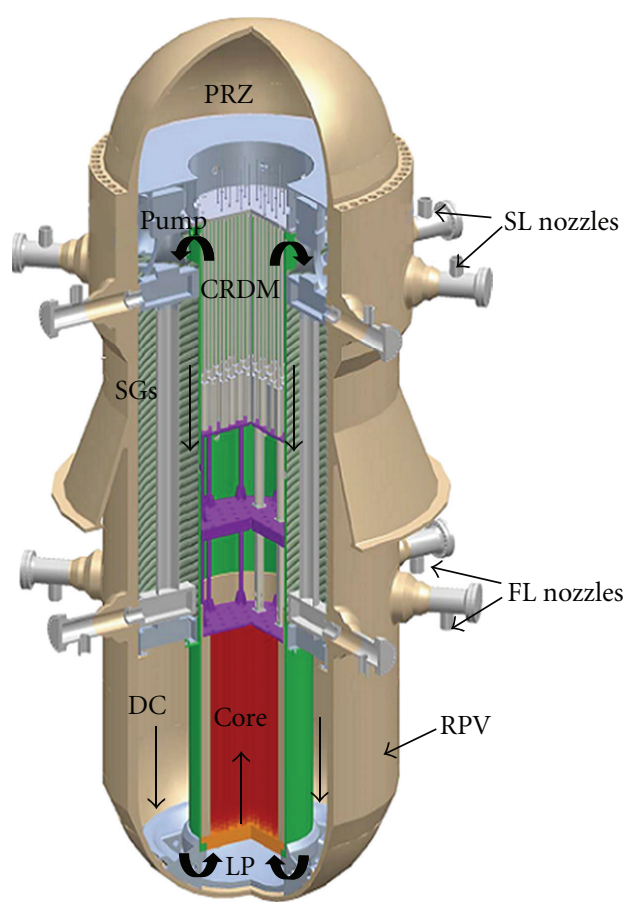

FIGURE 1: IRIS integral layout.



FIGURE 2: IRIS containment systems.

rejection to the RWST prevents containment overpressurization and contributes to core cooling also thanks to dynamic coupling between the primary and containment systems.

The DBA simulation on the facility allowed to understand the transient plant behaviour and the mutual system interaction. The comparison with the IRIS results led to running many sensitivity cases that required the SPES3 design review for better matching the IRIS transients.

The SPES3 tests will provide a qualified data base for the assessment of codes to be used in the reactor safety analyses.

The SPES3 facility is under construction, based on the IRIS reactor design. The availability of such a complex plant opens the way to other possibilities of exploitation, and

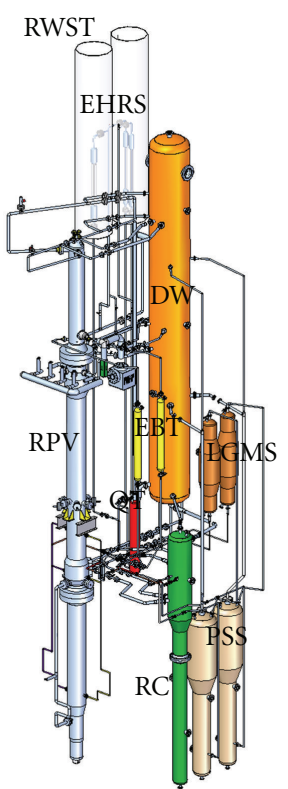

FIgURE 3: SPES3 facility layout.

studies are foreseen for using it in a wider field of application for integral layout SMR simulation [8].

\section{IRIS Plant and SPES3 Facility Layout and Nodalization}

The IRIS pressure vessel and containment are shown in Figures 1 and 2, whereas the SPES3 facility is presented in Figure 3.

The SPES3 facility reproduces all parts and components of the IRIS plant with $1: 100$ volume scaling factor, 1:1 elevation scaling factor, and prototypical fluid and thermal-hydraulic conditions. The reactor vessel includes the internals, consisting of the electrically heated core simulator, the riser with control rod device mechanisms, the pressurizer, the pump suction plenum, the helical coil steam generators, the downcomer, and the lower plenum. Three SGs simulate the eight IRIS SGs. A pump, located outside of the RPV, for room reasons, and connected to it by pipes, simulates eight IRIS pumps. Two emergency boration tanks are simulated and connected to the DVI lines, devoted to direct injection of emergency fluid into the vessel. Three secondary loops simulate four IRIS loops. Each secondary loop is simulated up to the main isolation valves and includes the feed line, the SG, the steam line, and the emergency heat removal system with a vertical tube heat exchanger immersed in a refuelling water storage tank. The IRIS spherical containment compartments are simulated by tanks, connected to each other by pipes and to the RPV by break lines $[4,5]$. They include dry-well and reactor cavity, representing the dry zone surrounding the RPV, respectively above and below the mid-deck plane; pressure suppression systems representing the wet zone around the lower part 




FIGURE 4: IRIS primary and secondary circuit nodalization for RELAP5 code.

of the RPV, suitable to dump pressure in case of containment pressurization; long-term gravity make-up systems representing the cold water reservoir to be poured into the RPV when depressurized. The two stages of the automatic depressurization system are simulated, connected to the pressurizer top, with stage I discharging into the quench tank and stage II directly connecting RPV and DW at high plant elevation.

The facility allows to test both LOCAs and secondary side breaks (DBA and BDBA) as well as to perform separate effect tests on particular components such as SG-EHRS thermally coupled to RWST.

The IRIS nodalization was developed in two parts: the primary and secondary circuits for the RELAP5 code and the containment system for the GOTHIC code (Figures 4 and 5). The RELAP5 nodalization includes 1845 volumes, and 1940 junctions, 1015 heat structures with 8600 mesh points, while the GOTHIC model includes 85 volumes, 28 junctions, and 57 heat structures.

The SPES3 nodalization was completely developed for the RELAP5 code (Figures 6, 7, and 8). It includes 1499 volumes, 1639 junctions, 1839 heat structures, and 19322 mesh points.

\section{Design-Calculation Feedback Process for SPES3 Facility Final Design}

The RELAP5 model for SPES3 was initially developed on the basis of the preliminary design of the facility, and the steady-state conditions are based on the actual IRIS nominal operation [9]. Five DBAs were simulated with particular attention to the occurring phenomena and sequence of events. In particular, three SB-LOCAs and two secondary side breaks were simulated, according to the specified test matrix [10].

Once the phenomena occurring in the DBAs were investigated, attention was focused on the most challenging transient scenario, the DVI line DEG break, for a direct comparison of the SPES3 and IRIS results.

WEC, in collaboration with the University of Pisa and Politecnico di Milano, developed the Fractional Scaling Analysis for IRIS and SPES3. The method, based on system and time sequence decomposition, allowed to identify the parameters mostly affecting the transient and to quantify the distortions between IRIS and SPES3 simulations introduced by such parameters (e.g., containment tank metal mass, heat transfer at core side wall, etc.). 


\begin{tabular}{|c|c|}
\hline 11 & Environment \\
\hline
\end{tabular}



FIGURE 5: IRIS containment nodalization for GOTHIC code.

The first application of the DVI line DEG break evidenced important differences on containment pressure, especially in early phase of the accident, at pressure peak, and also on the long term.

The need of understanding the reasons and reducing discrepancies led to performing a series of sensitivity cases on SPES3 containment, making SPES3 response closer to reactor one, and finalizing the facility design $[11,12]$.

The main events, identified in the DVI line break transient, are listed below for better understanding all sensitivity analyses and the design-calculation feedback process. Approximate timing of events is reported too. The long-term phase of the transient was simulated to verify the safe, stable plant operation.

(i) The break opening ( $0 \mathrm{~s})$ causes the RPV blowdown and depressurization, containment pressurization, steam dumping into PSS with air build-up at PSS top, and consequent pressurization;

(ii) the signal of high containment pressure $(\sim 30 \mathrm{~s})$ triggers the reactor scram, the secondary loop isolation, and the actuation of two out of four EHRSs;

(iii) the signal of low PRZ water level $(\sim 120 \mathrm{~s})$ triggers the pump coastdown, and the natural circulation in the core is guaranteed through the check valves, connecting riser and downcomer at one-third of the SG height;

(iv) the signal of low PRZ pressure ( $200 \mathrm{~s})$ actuates the remaining EHRS and triggers the ADS stage I, to help
RPV depressurization, and the EBT intervention, to inject cold water into the primary circuit;

(v) the signal of low differential pressure between RPV and DW ( $2250 \mathrm{~s})$ triggers the LGMS injection into the DVI line and opens the valves connecting RC and DVI line to allow water reverse flow from the containment to the primary side;

(vi) when PSS pressurization is sufficiently high, cold water flows from PSS to DW (3500 s), increasing the RC flooding and allowing water to enter the RPV;

(vii) the signal of low LGMS mass ( 25000 s) opens the ADS stage II with possible reverse steam flow from DW to RPV;

(viii) on the long term (simulation up to $100000 \mathrm{~s}$ ), the plant is cooled by EHRSs that reject core decay heat to RWST.

The starting point for the sensitivity analyses was the comparison between cases SPES3-97 and IRIS-HT1 results, which showed qualitatively good agreement in occurring phenomena, but also quantitative discrepancies in containment pressure, affecting the sequence of events and transient evolution (Figure 9).

A series of parameters identifying and potentially affecting containment pressure is: (a) SPES3 containment overvolume of about $10 \%$ with respect to $1: 100$ scaled IRIS; (b) SPES3 containment metal mass greater than IRIS for mechanical resistance to the same design conditions; (c) 




FIGURE 6: SPES3 primary circuit nodalization for RELAP5 code.

SPES3 component surface-to-volume ratio ten times greater than IRIS, due to volume scaling and component height conservation; (d) containment metal structure temperature; (e) containment piping pressure drops; (f) EHRS and RWST modelling and heat transfer coefficients.

A synthesis of the performed sensitivity cases on SPES3 is reported in Table 1, where they are grouped according to the investigated parameters. A synthesis of IRIS cases, utilised for the comparison, is reported in Table 2.
A reduction of DW volume, for correctly scaling IRIS ( $1: 100)$, did not provide great improvements (a few percent) in the containment pressure response. An improvement was observed only in the long term related to lower heat losses to environment due to DW size reduction (Figure 10).

In order to compensate for the extra surface in SPES3, a thermal insulation of DW inner surface was tested with different thickness of Aluminium Silicate Rescor 902. As shown in Figure 11, the introduction of an increasing 

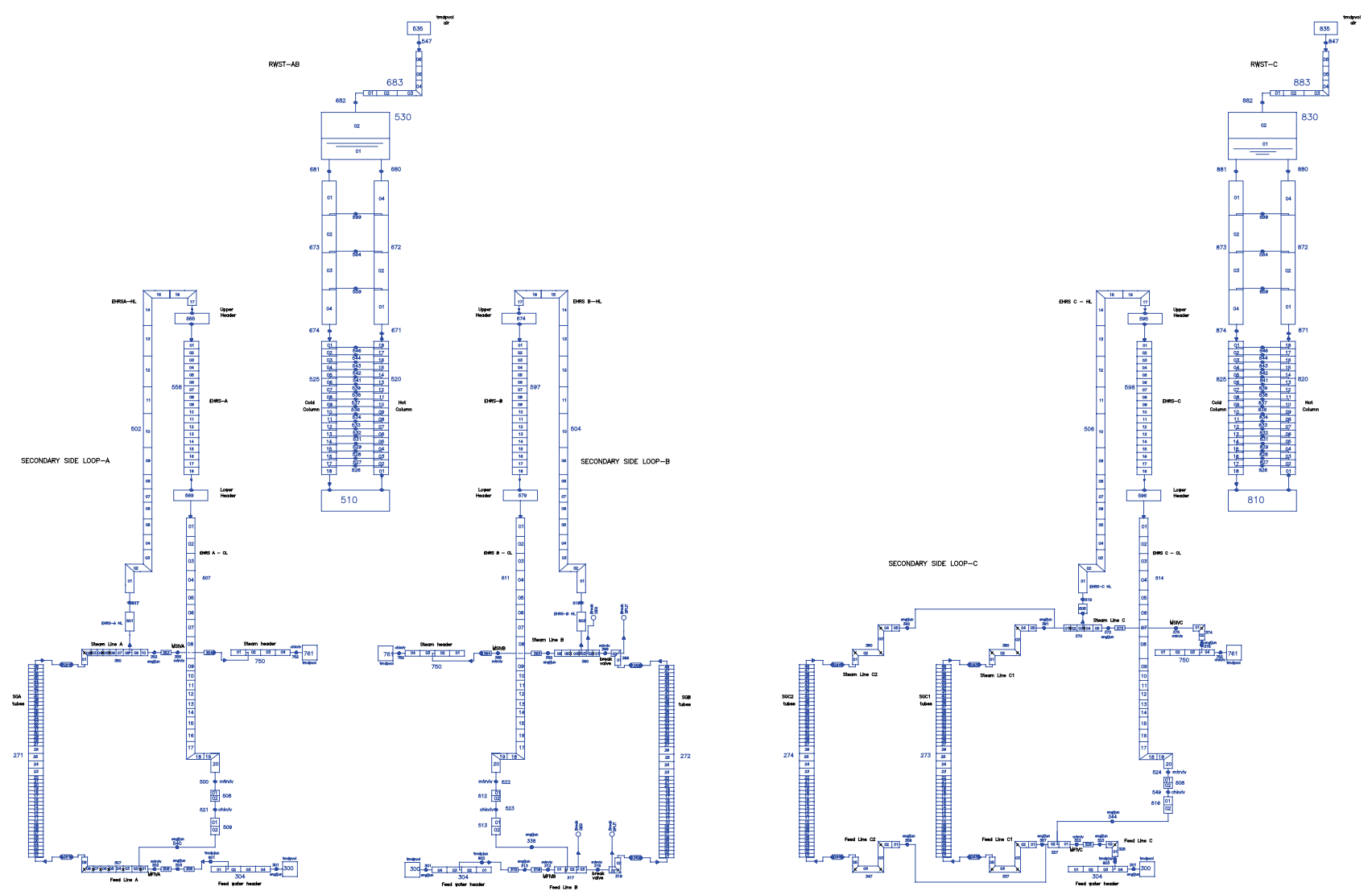

FIgURE 7: SPES3 secondary circuit and EHRS nodalization for RELAP5 code.

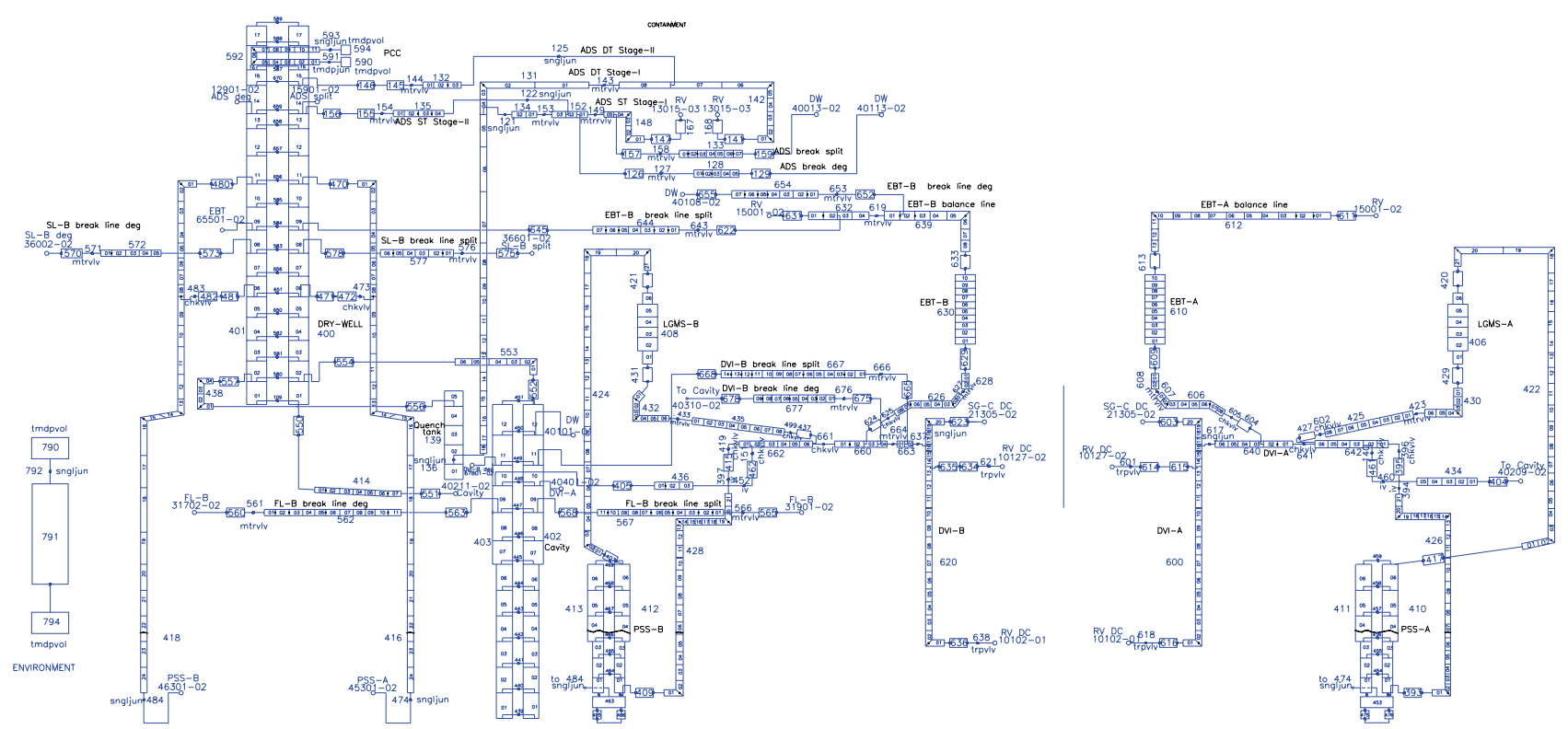

FIgURE 8: SPES3 containment nodalization for RELAP5 code.

thickness of thermal insulation increased pressure in the very short term, but the additional mass reduced the containment pressure peak. The result was that the DW insulation led to worse effects on pressure than with noninsulated DW, showing that masses have larger effects than surfaces.
The influence of DW heat structure mass on containment pressure response was investigated by reducing DW thickness by $40 \%$ ( $25 \mathrm{~mm}$ to $15 \mathrm{~mm}$ ), approximately corresponding to a design pressure of $1.5 \mathrm{MPa}$, instead of the original $2 \mathrm{MPa}$. As shown in Figure 12, pressure increase in the early 


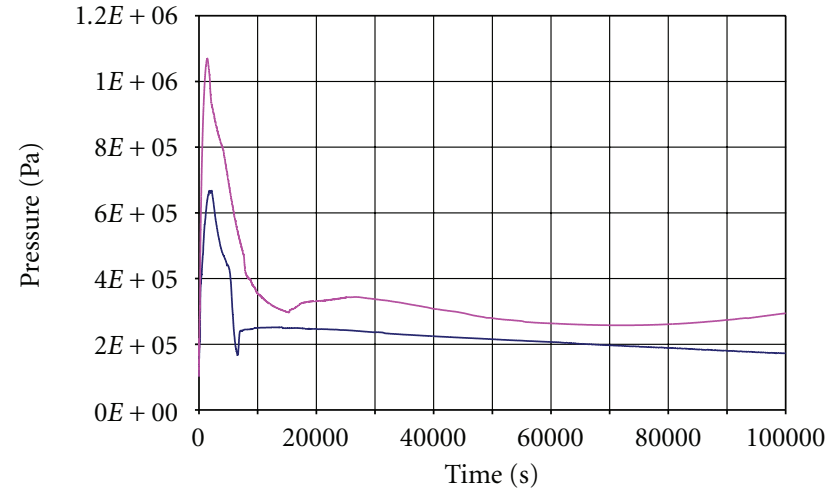

\begin{tabular}{ll} 
p 401140000 & SPES3-97 \\
\hline PR1s54*1000 & IRIS-HT1
\end{tabular}

FIGURE 9: SPES3-97 and IRIS-HT1 DW pressure. Note: The IRIS Drywell Volume was subdivided in $4 \times 4 \times 4$ sub-volumes in the three directions, marked $1 \mathrm{~s} 1,1 \mathrm{~s} 2 \ldots$ up to 1 s64. Pressure from a cell at the top of the model was used as reference.
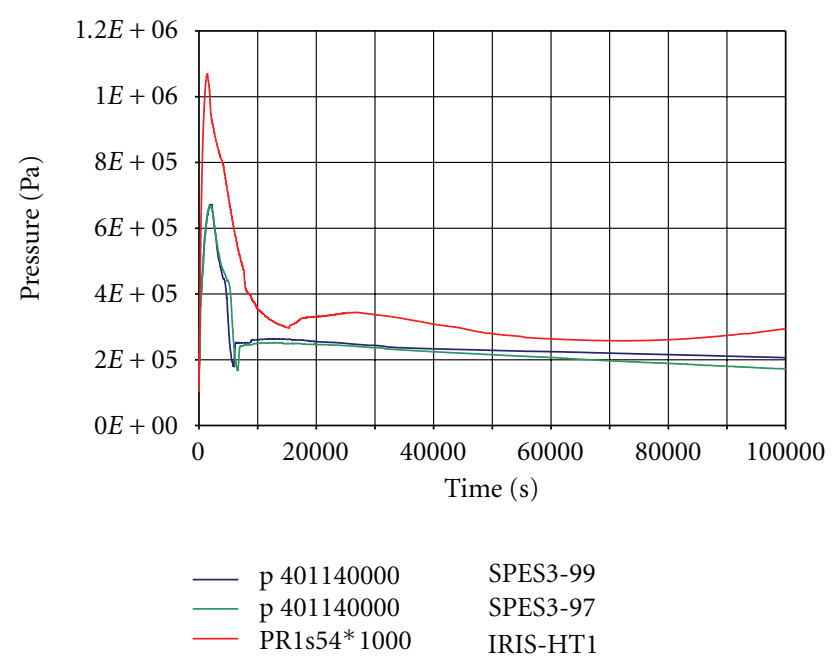

FIgURE 10: SPES3-97, 99 and IRIS-HT1 DW pressure.

phase of the transient was steeper and pressure peak higher. Containment pressure was still below the IRIS one, showing that such DW metal mass reduction was not enough to have the desired pressure response.

A further DW mass reduction was performed in a theoretical case, where concrete plus carbon steel IRIS DW equivalent mass was distributed on SPES3 DW surface, resulting in a thickness of $10 \mathrm{~mm}$ AISI 304. As shown in Figure 13, the further DW mass reduction allowed to get pressure values closer to IRIS both in the early phases of the transient and at the pressure peak, but still below IRIS pressure. That showed that other parameters affected the results.

An attempt to investigate how a greater DW volume reduction affects containment pressure was performed by scaling it 1:150 with respect to IRIS. Figure 14 shows a pressure gain only in the early phases of the transient
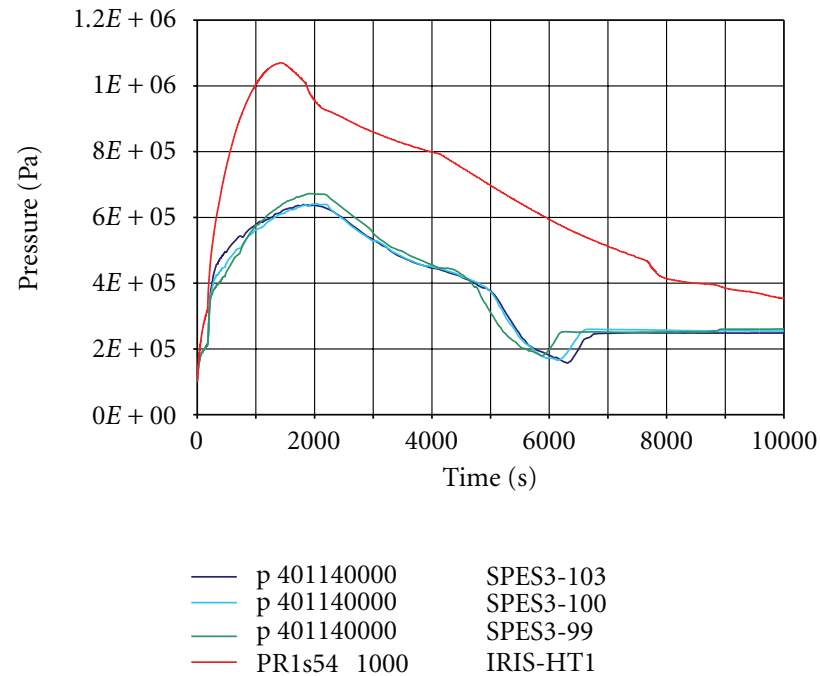

FIGURE 11: SPES3-99, 100, 103 and IRIS-HT1 DW pressure (short term).

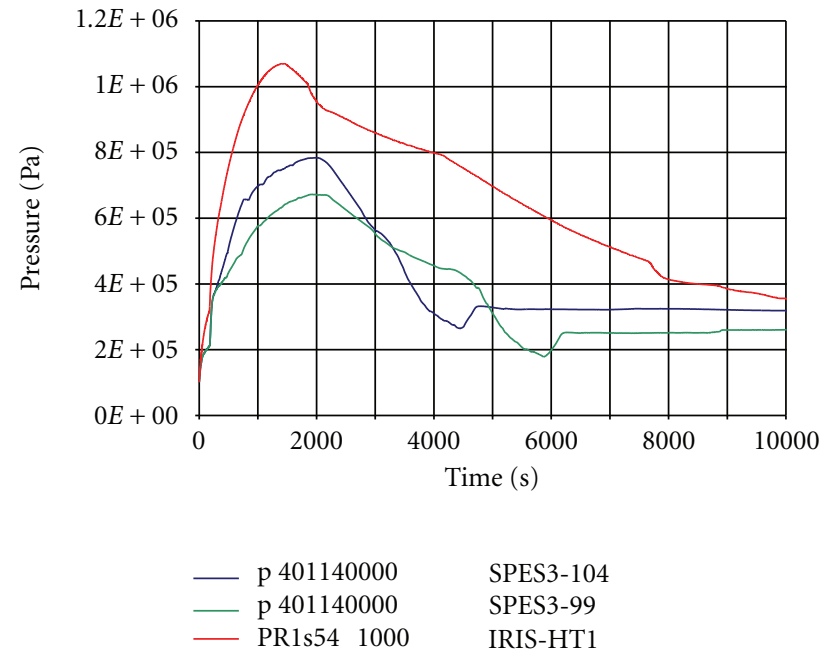

FIGURE 12: SPES3-99, 104 and IRIS-HT1 DW pressure (short term).



FIGURE 13: SPES3-99, 105 and IRIS-HT1 DW pressure (short term). 


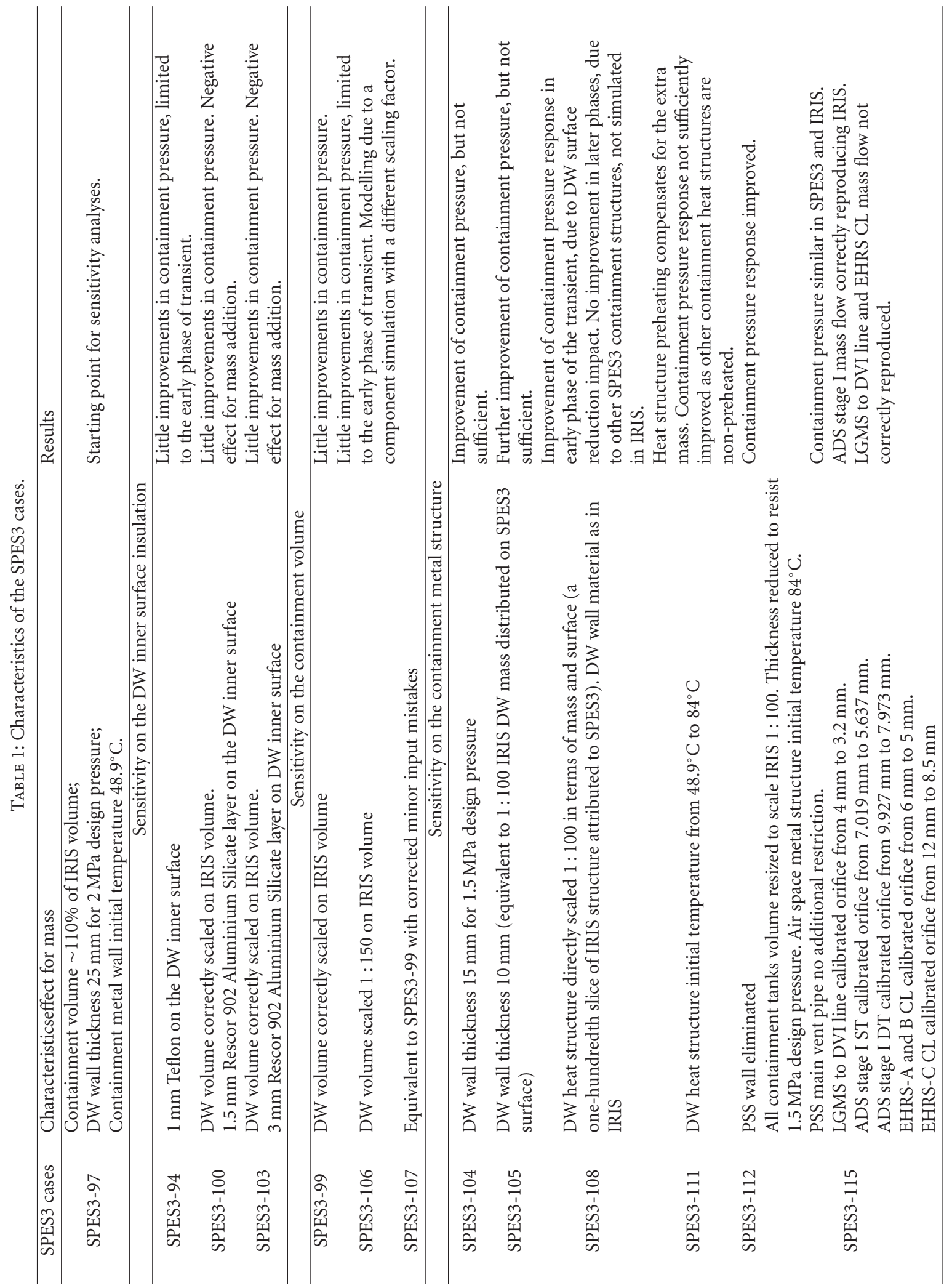




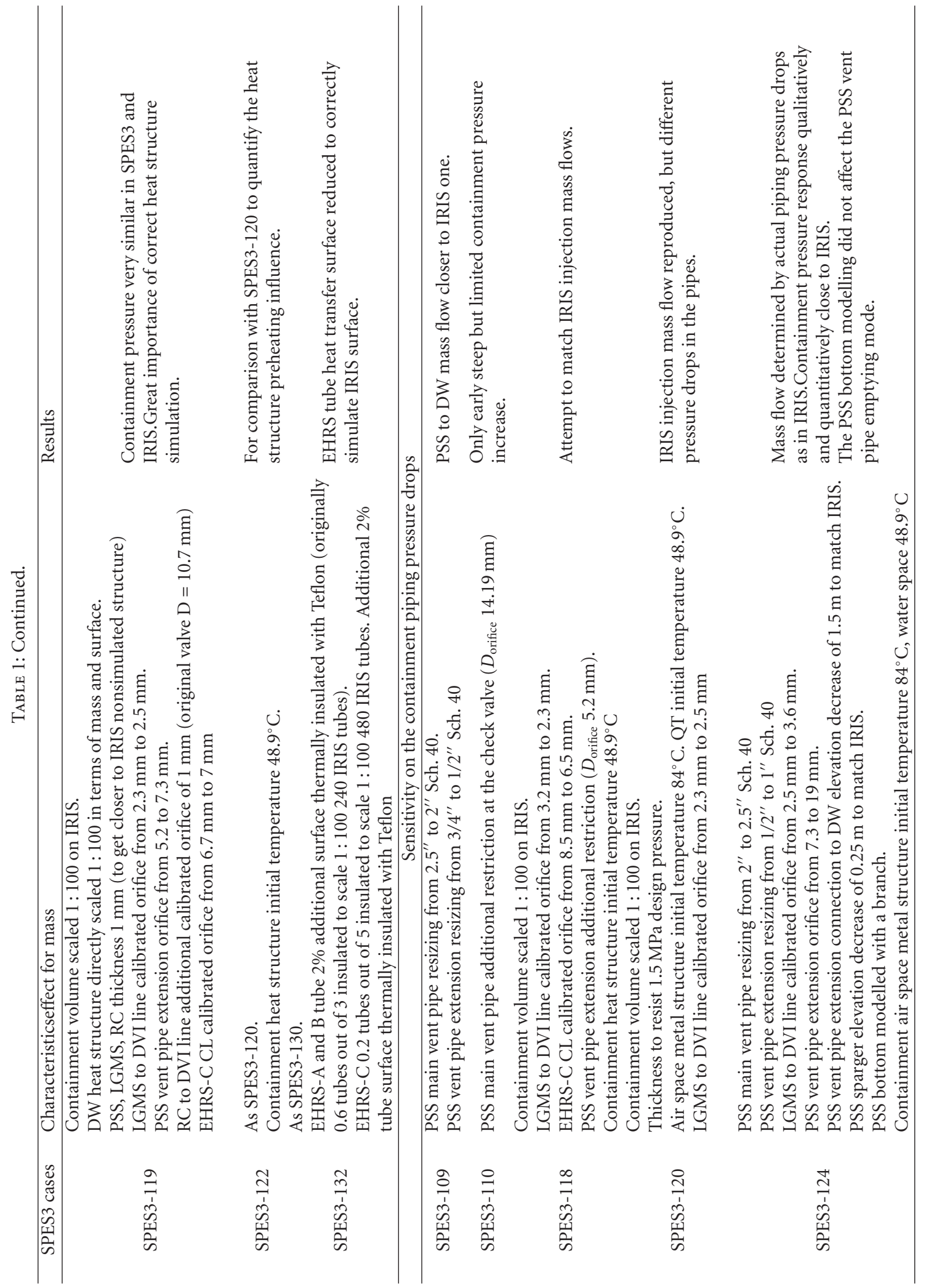




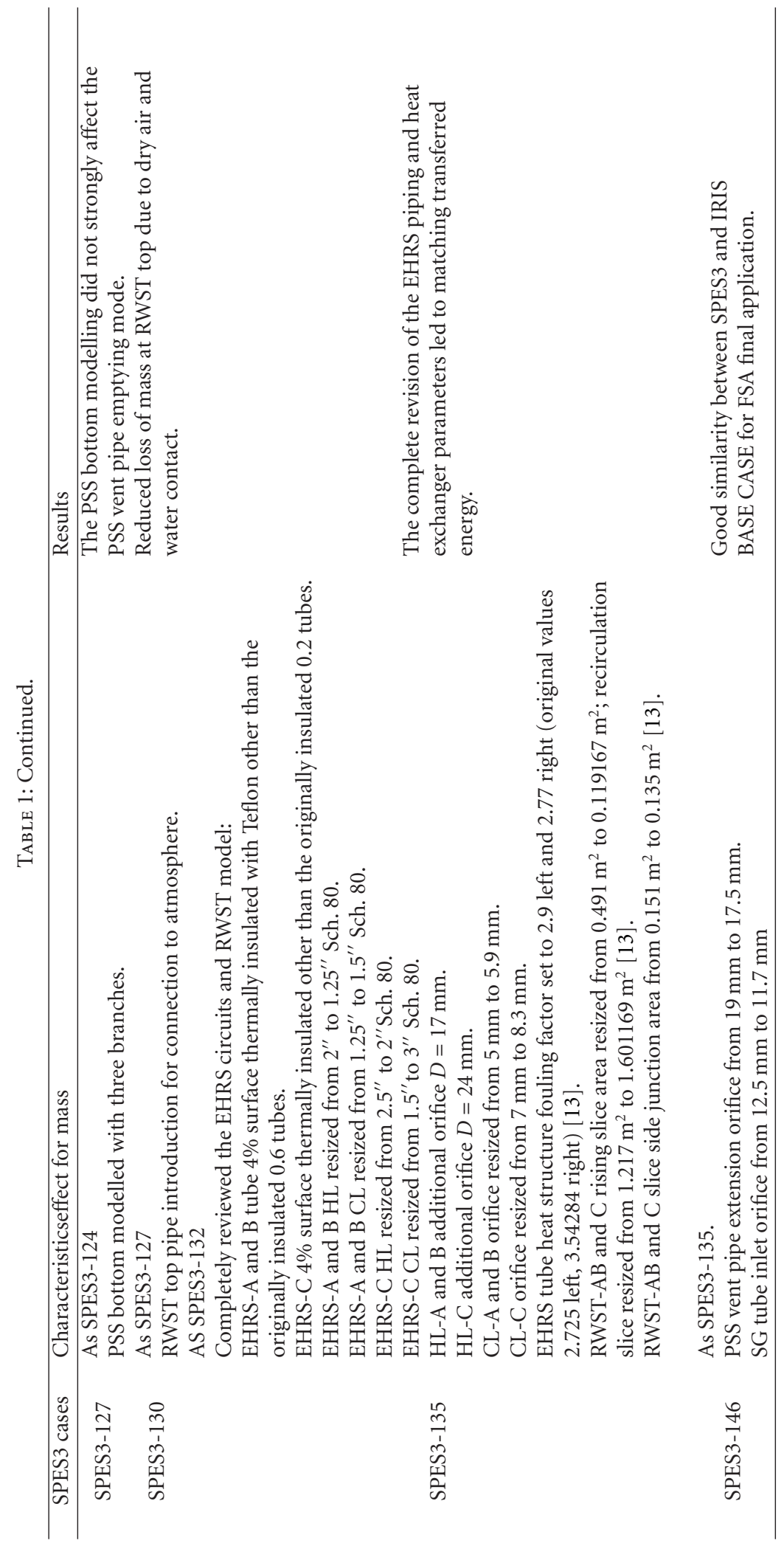


TABLE 2: Characteristics of the IRIS cases.

\begin{tabular}{lll}
\hline IRIS cases & Characteristics & Results \\
\hline IRIS-HT1 & Containment heat structures simulated only for the DW. & Starting point for comparison with SPES3. \\
\hline & $\begin{array}{l}\text { Heat structures added to all containment compartments and secondary } \\
\text { sidepiping. }\end{array}$ & Similar containment pressure response with \\
IRIS-HT5g & $\begin{array}{l}\text { PSS main vent pipe connection to DW rise of } 4 \mathrm{~m} . \\
\end{array}$ & SPES3. \\
& RWS sparger set at 0.75 m from PSS bottom. & \\
\hline
\end{tabular}

SG tubes inner layer removed which simulated the Fouling.

ADS stage II actuation signal corrected to intervene on low LGMS mass.

RWST remodelling according to PERSEO area ratio and HTC calibration

on experimental data. EHRS heat transfer parameters set as in SPES3 (by

HT6_rwstc multiplier fouling factors) $[12,13]$.

Better matching of EHRS long-term energy

RWST top pipe introduction for connection to atmosphere. transfer to RWST.

Correction of energy transfer parameters at the GOTHIC and RELAP5 code couplings.

IRIS- $\quad$ Corrected elevation difference between the RELAP5 and GOTHIC parts of

HT6_rwstcla the model: the ADS stage I vent pipe end should be $0.5 \mathrm{~m}$ from QT bottom (it was connected to QT top); LGMS tanks rise of $0.75 \mathrm{~m}$.

Results very similar to IRIS-HT6_rwstc BASE CASE for FSA final application.



\begin{tabular}{ll}
- p 401140000 & SPES3-106 \\
- p 401140000 & SPES3-104 \\
\hline PR1s54 1000 & IRIS-HT1
\end{tabular}

FIGURE 14: SPES3-104, 106 and IRIS-HT1 DW pressure (short term).

with a lower peak value. No improvement was obtained by overreducing the DW volume with a scaling factor different from $1: 100$.

A theoretical case, where IRIS DW structures were directly scaled $1: 100$ in mass and surface, was investigated. A one-hundredth vertical slice of IRIS DW structures was attributed to SPES3 DW, maintaining the same thickness and material composition. Figure 15 compares two cases with equivalent heat structure masses, but different surfaces and material properties. Pressure increase was similar in IRIS and SPES3, in the early phase of the transient, when surface has a greater impact, but later energy transfer to heat structures prevailed and SPES3 pressure did not increase as expected, with all SPES3 containment structures being completely simulated against the only IRIS DW structure simulation. Moreover, gas space volume at the PSS and LGMS top was about $14 \%$ higher in SPES3 than IRIS, so limiting
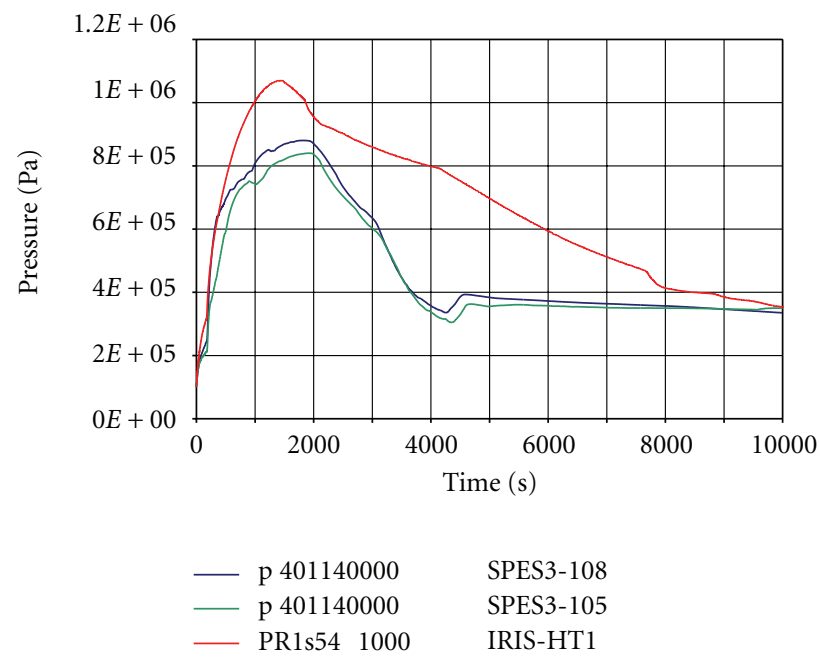

Figure 15: SPES3-105, 108 and IRIS-HT1 DW pressure (short term).

the containment pressure peak. Containment pressure trend showed also differences in the depressurization phase, related to steam condensation in RC and DW due to broken loop LGMS water entering the RC $(\sim 2000 \mathrm{~s}$ in SPES3) through the DVI break line, containment side, and PSS injection into the DW ( $3000 \mathrm{~s}$ in SPES3). Injection mass flows are shown in Figures 16 and 17, and they depended on different pipe pressure drops and containment pressurization.

An attempt to make closer SPES3 and IRIS PSS to DW injection mass flows was performed: size of PSS main vent pipe and extension was decreased and the results compared with a base case (SPES3-107) equivalent to SPES99, where minor input mistakes were corrected. PSS injection results were effectively closer to IRIS with consequent slower containment depressurization (Figures 18 and 19).

The attempt was performed to see how a restriction at the PSS main vent pipe check valve affects the steam-air transfer 

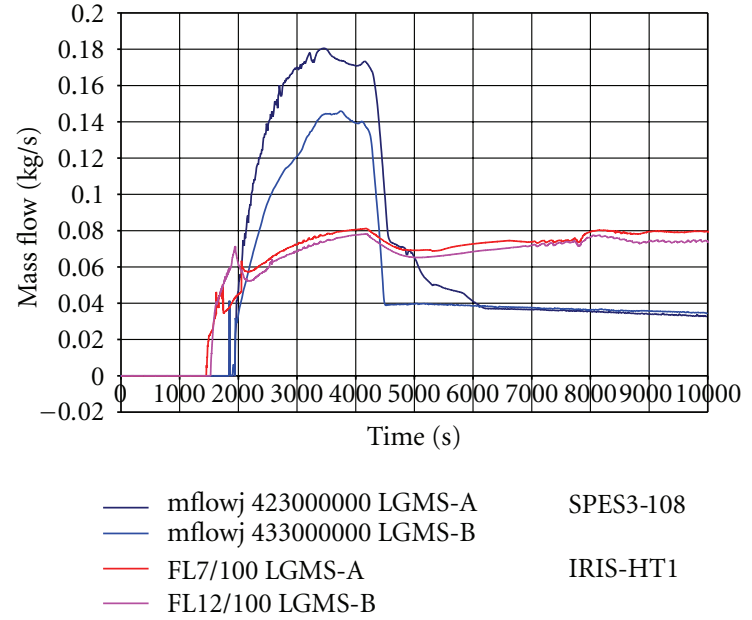

SPES3-108

IRIS-HT1

FIGURE 16: SPES3-108 and IRIS-HT1 LGMS to DVI injection mass flow (short term).



$$
\begin{aligned}
& \text { — mflowj } 47002+473 \text { VENT-A } \\
& \text { - mflowj } 48002+483 \text { VENT-B } \\
& \text { - FV + FL + FD04 VENT-A } \\
& \text { FV + FL + FD09 VENT-B }
\end{aligned}
$$

SPES3-108

IRIS-HT1

FIgure 17: SPES3-108 and IRIS-HT1 PSS to DW injection mass flow (short term). Note: for IRIS, the total mass flow (FL + FV + FD) is obtained by the sum of phasic mass flows (liquid, gas and droplets.

from DW to PSS and eventually rise DW pressure. The result was a steep but limited pressure increase (Figure 20).

The impossibility of reducing the DW thickness under $15 \mathrm{~mm}$, to resist $1.5 \mathrm{MPa}$ design pressure, led necessarily to an excess of mass with respect to IRIS $1: 100$ scaled mass. In SPES3-105 case, the IRIS scaled mass was distributed on the SPES3 DW surface obtaining an equivalent thickness of $10 \mathrm{~mm}$. The possibility of compensating for $5 \mathrm{~mm}$ extra mass, by preheating the DW heat structures, was investigated. The preheating temperature of $84^{\circ} \mathrm{C}$ was estimated by an energy balance between the cases with $10 \mathrm{~mm}$ and $15 \mathrm{~mm}$ thickness from the specified initial temperature of $48.9^{\circ} \mathrm{C}$ and regime temperature of $172^{\circ} \mathrm{C}$ after the heat-up transient. Figure 21 compares the cases with $15 \mathrm{~mm}$ (SPES3104), $10 \mathrm{~mm}$ (SPES3-105), and $15 \mathrm{~mm}$ (SPES3-111) preheated DW thickness. The $10 \mathrm{~mm}$ and $15 \mathrm{~mm}$ pre-heated
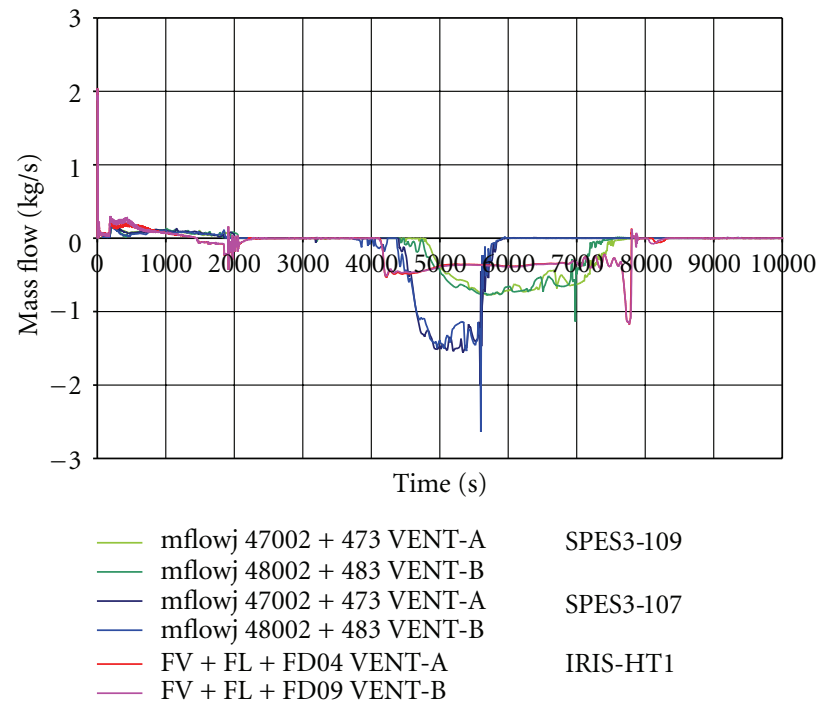

FIgure 18: SPES3-109, 107 and IRIS-HT1 PSS to DW injection mass flow (short term).
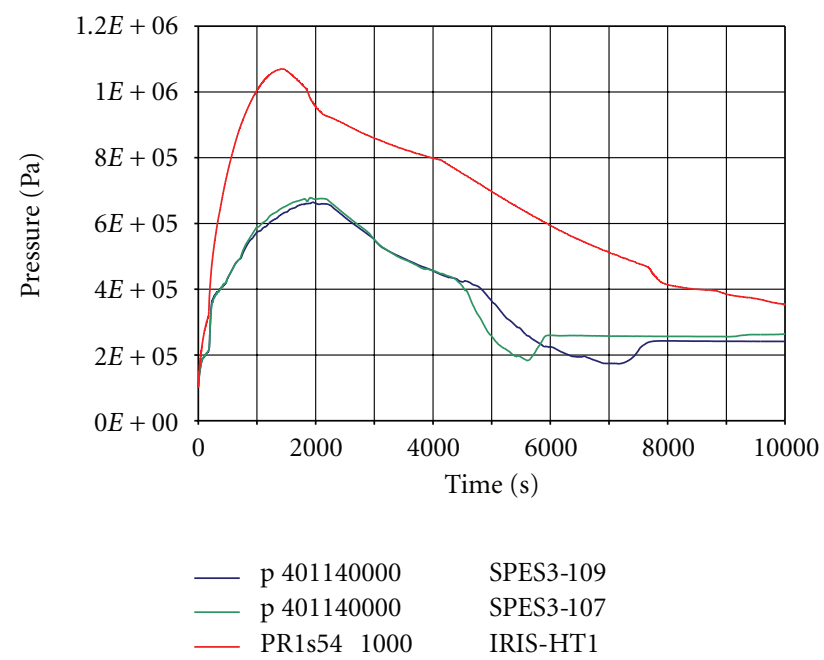

FIGURE 19: SPES3-109, 107 and IRIS-HT1 DW pressure (short term).

DWs are equivalent showing that heat structure preheating compensates for the excess of mass in SPES3. Only DW preheating is not enough to have the same IRIS pressure response.

The comparison between the cases with and without PSS heat structures allowed to quantify the phenomenon of air cooling when steam-air mixture flowed from DW to PSS. The run was interrupted by a nonconvergence error on noncondensable gas properties in the PSS, but available results allowed to evaluate the pressure gain, with respect to the theoretical case with $1: 100$ IRIS DW volume and surface scaled structures, as shown in Figure 22.

In order to reduce distortions on pressure as much as possible, related to scaling mismatching, all the SPES3 containment compartments were scaled $1: 100$ on IRIS volumes and all thicknesses were sized to resist $1.5 \mathrm{MPa}$ 


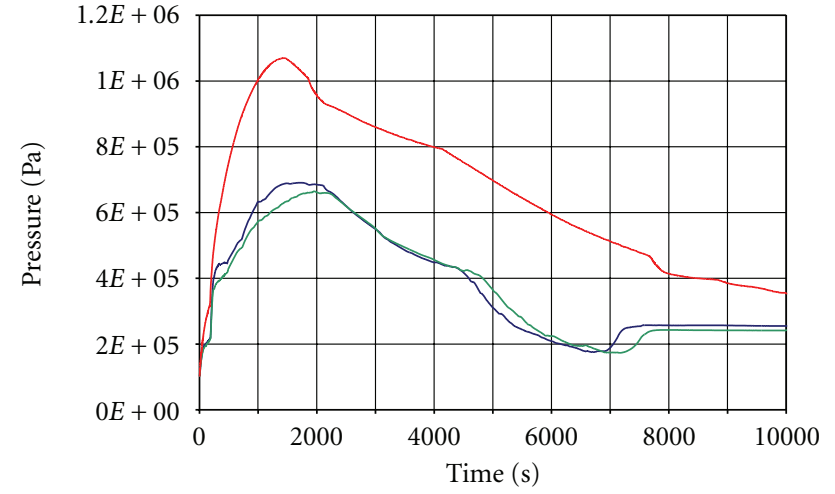

\begin{tabular}{lll}
- & p 401140000 & SPES3-110 \\
\hline & p 401140000 & SPES3-109 \\
& PR1s54 1000 & IRIS-HT1
\end{tabular}

Figure 20: SPES3-110, 109 and IRIS-HT1 DW pressure (short term).

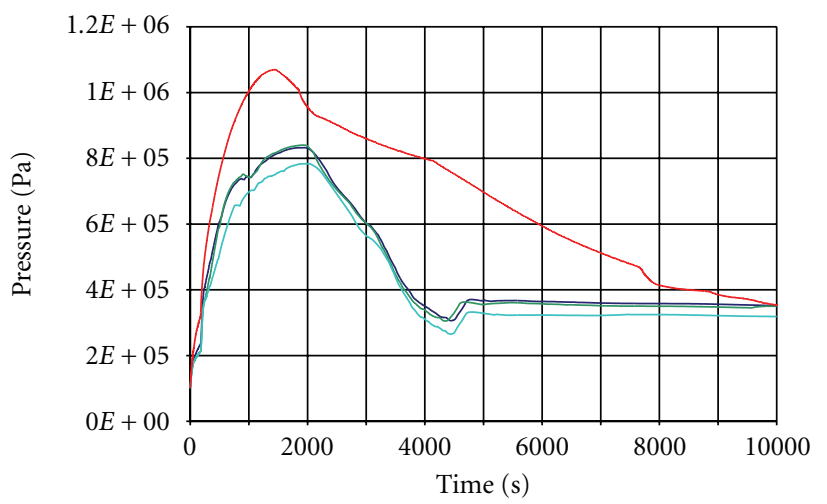

FIGURE 21: SPES3-111, 105, 104 and IRIS-HT1 DW pressure (short term).

pressure, so limiting the thermal inertia of the metal walls. In particular, the containment air zone heat structures were preheated at $84^{\circ} \mathrm{C}$, while those in the liquid zone were kept at $48.9^{\circ} \mathrm{C}$. Moreover, the calibrated orifices on the LGMS to DVI lines, the ADS stage I, and EHRS-C CL were resized to match IRIS mass flows. Figure 23 shows that, notwithstanding a slower DW pressure increase, that case is similar to the case with IRIS DW scaled $1: 100$ in mass and surface (SPES3-108), confirming that containment volume resizing and heat structure preheating are good solutions toward IRIS containment pressure response. Orifice resizing was not enough to match the IRIS LGMS to DVI and EHRS-C CL mass flows, while it was correct to scale ADS stage I mass flow (Figure 24), even if a stronger water entrainment was evidenced in IRIS at the second flow peak.
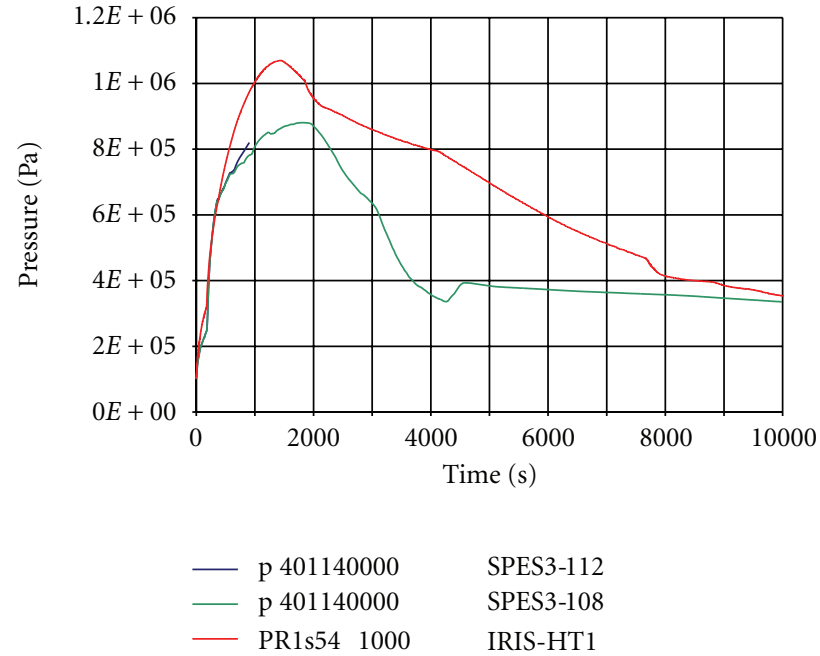

FIgURE 22: SPES3-112, 108 and IRIS-HT1 DW pressure (short term).
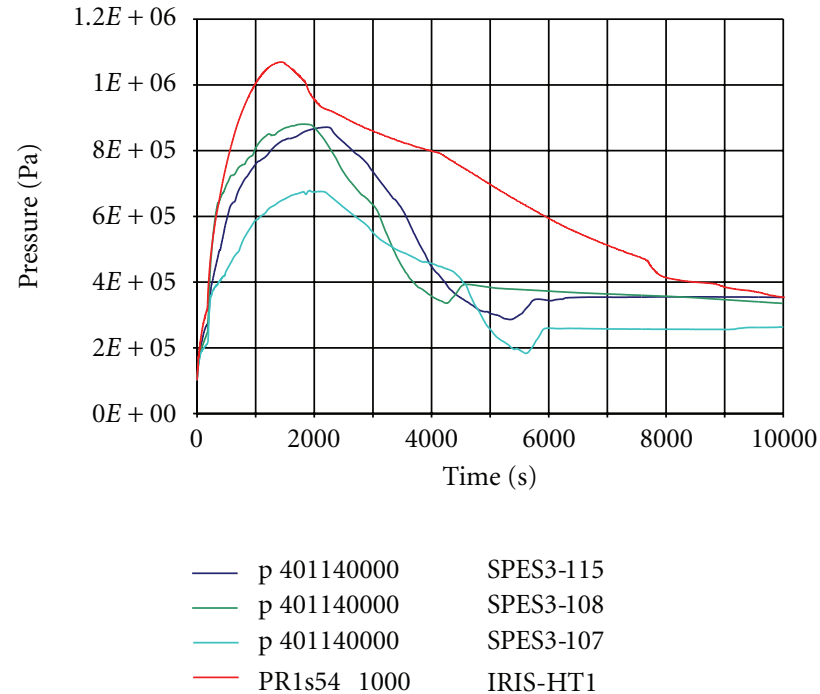

FIGURE 23: SPES3-115, 108, 107 and IRIS-HT1 DW pressure (short term).

Further calibrations of the injection line orifices were performed that evidenced contact condensation stronger in SPES3 (RELAP5) than in IRIS (GOTHIC).

A case was run where IRIS containment heat structures were reproduced on SPES3 with the DW 1:100 scaled in mass and surface and all other tanks with $1 \mathrm{~mm}$ thick walls to avoid code convergence errors in case of complete heat structure removal. Figure 25 shows very similar SPES3 and IRIS containment pressure rising phase and a pressure peak only $0.1 \mathrm{MPa}$ lower in SPES3 than in IRIS, demonstrating the importance of a correct simulation of the heat structures.

The containment piping orifice, sized to match IRIS injection mass flows, allowed a direct comparison between the plants, but it did not meet the piping pressure drop scaling criteria. It allowed to understand two important 


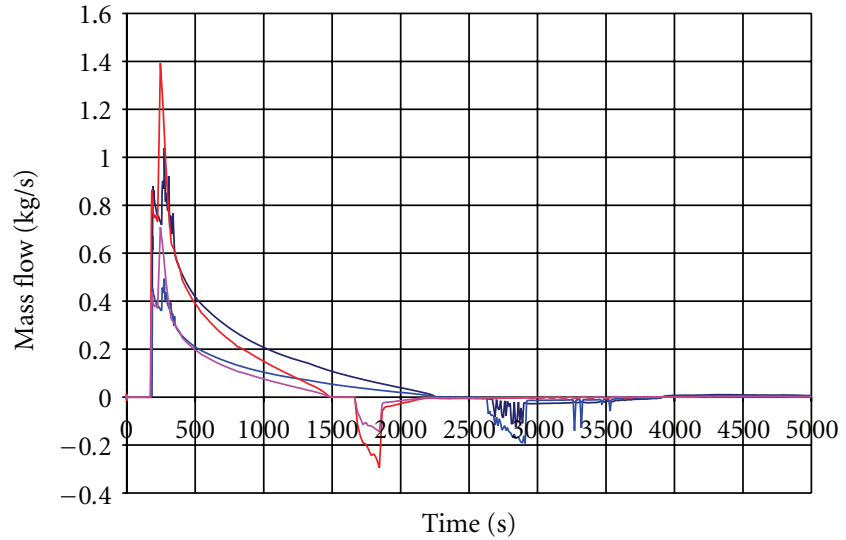

$\begin{array}{lll}\text { — mflowj } 143000000 \mathrm{DT} & \text { SPES3-115 } \\ \text { — mflowj } 153000000 \mathrm{ST} & \\ \text { — mflowj } 982+983 / 100 \mathrm{DT} & \text { IRIS-HT1 } \\ \text { — mflowj } 981 / 100 \mathrm{ST} & \end{array}$

FIgURE 24: SPES3-115 and IRIS-HT1 ADS stage I ST and DT mass flow (short term).

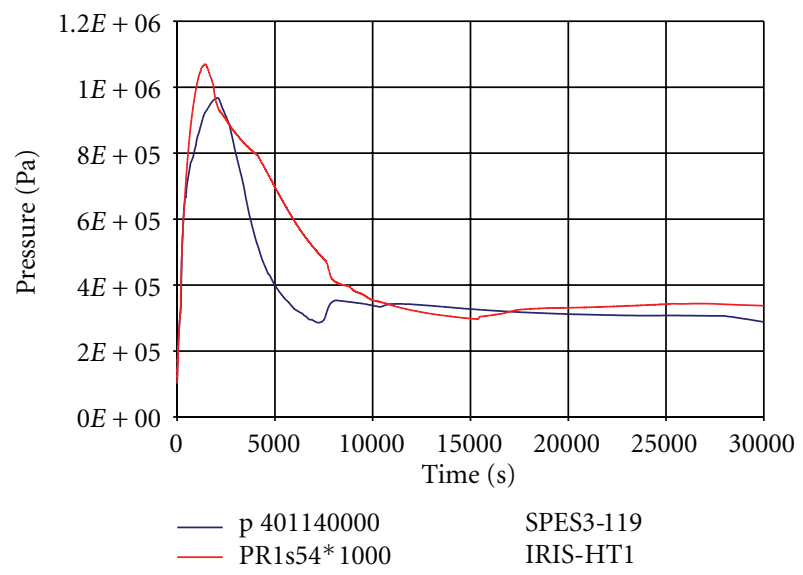

FIGURE 25: SPES3-119 and IRIS-HT1 DW pressure (short term).

differences related to the injection of LGMS into the DVI lines and of PSS into the DW. As shown in Figures 26 and 27, IRIS LGMS injection into the DVI line is always driven by differential pressure between LGMS and DVI line (until about 18700 s), instead in SPES3, such differential pressure extinguishes earlier (around 9200 s) and later LGMS injection is driven only by gravity with a large mass flow decrease. The reason for such early pressure equalization in SPES3 is related to the PSS injection stop, vent pipe emptying, and gas flow from PSS to DW. That phenomenon did not occur in IRIS, where the vent pipes did not empty avoiding air transfer from PSS to DW, keeping the PSS pressurized with respect to DW and DVI (Figure 28).

The sensitivity cases on containment tank geometry, heat structures, and piping pressure drops led to reviewing both the IRIS and SPES3 models in IRIS-HT5g and SPES3-124. All IRIS containment heat structures were simulated and SPES3 piping geometry was adjusted to match IRIS pressure drops.
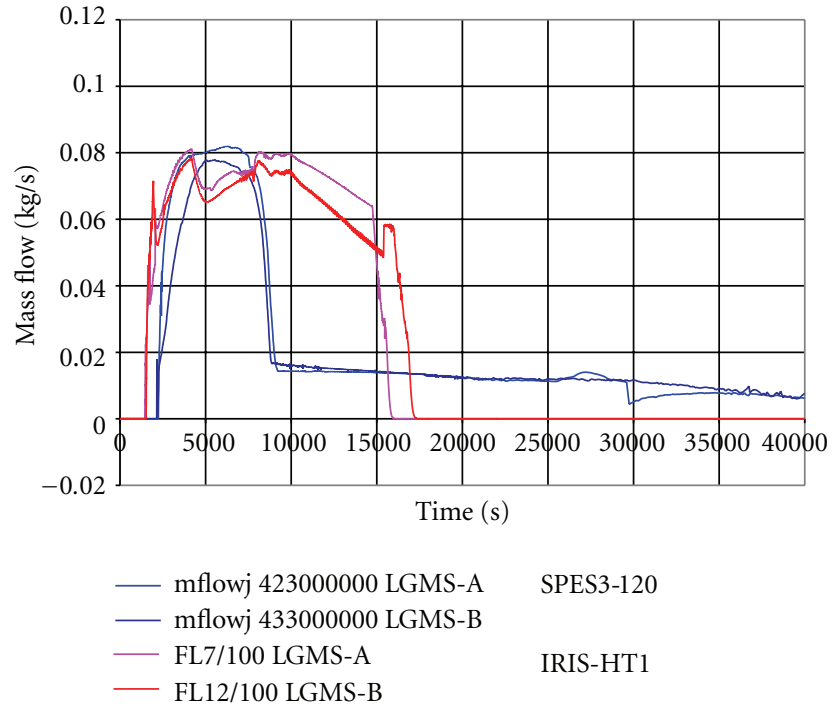

FIGURE 26: SPES3-120 and IRIS-HT1 LGMS injection mass flow.



\begin{tabular}{ll}
- p 406060000 LGMS-A & SPES3-120 \\
p 408060000 LGMS-B & \\
- p 6010100000 DVI-A & \\
p 630100000 DVI-B & \\
- PR7*1000 LGMS-A & IRIS-HT1 \\
PR8*1000 LGMS-B & \\
\hline P 604401 DVI-A & \\
P 62401 DVI-B &
\end{tabular}

FIGURE 27: SPES3-120 and IRIS-HT1 LGMS and DVI pressure.

Figure 29 compares SPES3 and IRIS containment pressures, showing a good qualitative and quantitative agreement. The LGMS to DVI and PSS to DW injection mass flows are shown in Figures 30 and 31. With the same simulated pressure drops in the piping, different values of mass flow are evidenced due to greater differential pressures in SPES3 between LGMS and DVI and PSS and DW. Various reasons could explain these differences and the most likely is the different code simulation of contact condensation with the consequent different pressurization of containment compartments. Remodelling of IRIS RWST led to similar RWST water temperatures, but greater exchanged power in SPES3 caused faster heat-up (Figure 32). 


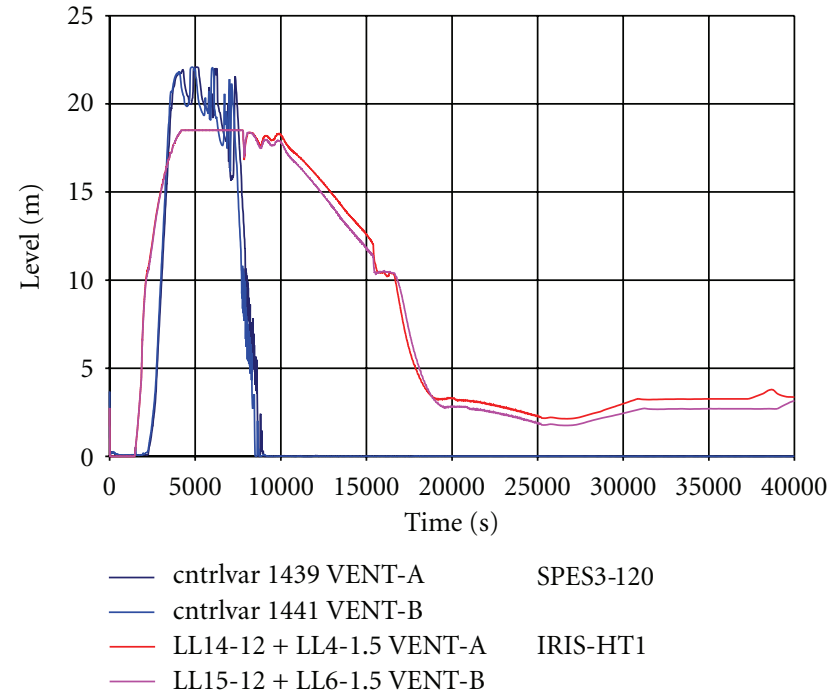

FIgURE 28: SPES3-120 and IRIS-HT1 PSS vent pipe level.

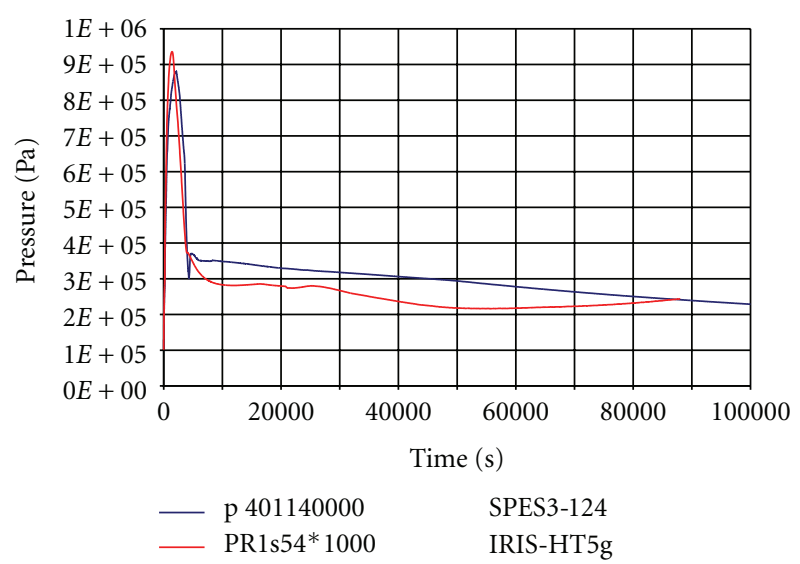

FIgURE 29: SPES3-124 and IRIS-HT5g DW pressure.
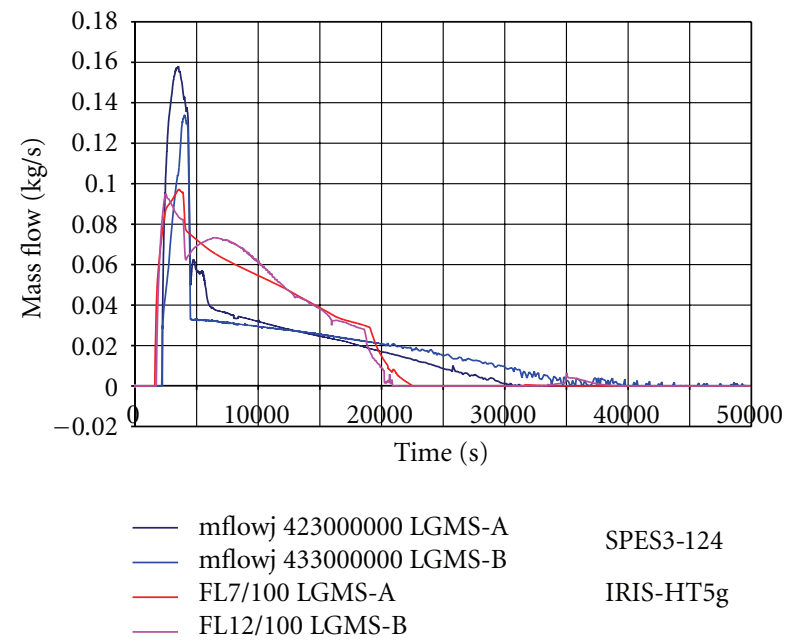

SPES3-124

IRIS-HT5g

FIgURE 30: SPES3-124 and IRIS-HT5g LGMS to DVI mass flow (short term).

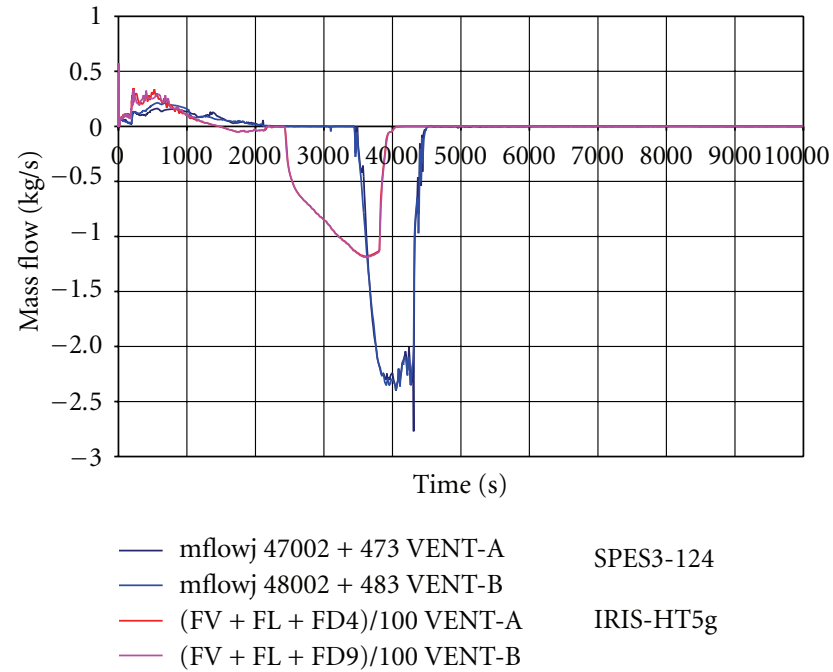

FIGURE 31: SPES3-124 and IRIS-HT5g PSS to DW mass flow (short term).
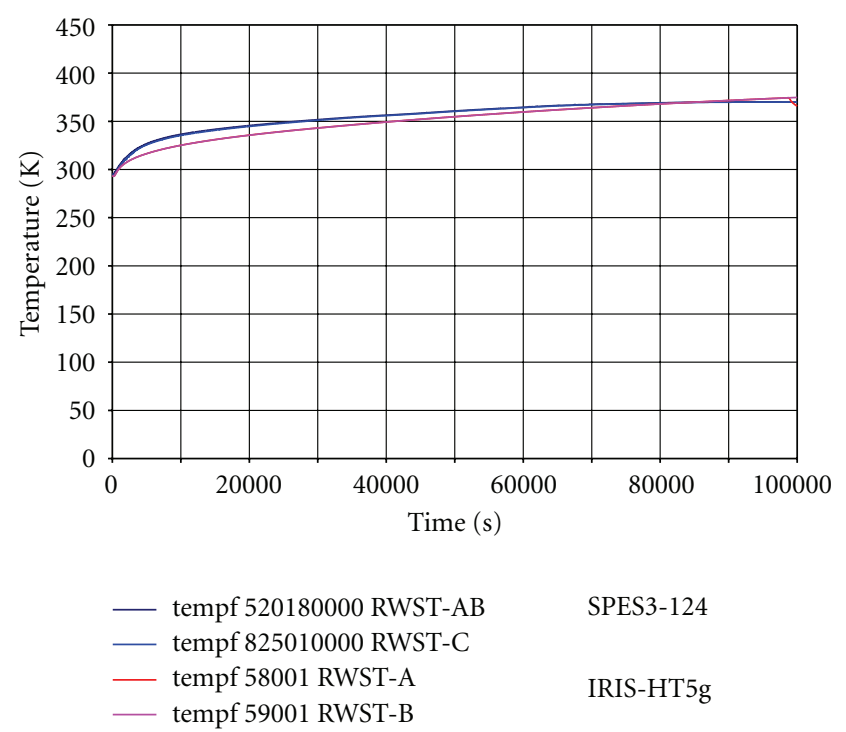

FIgURe 32: SPES3-124 and IRIS-HT5g RWST temperature.

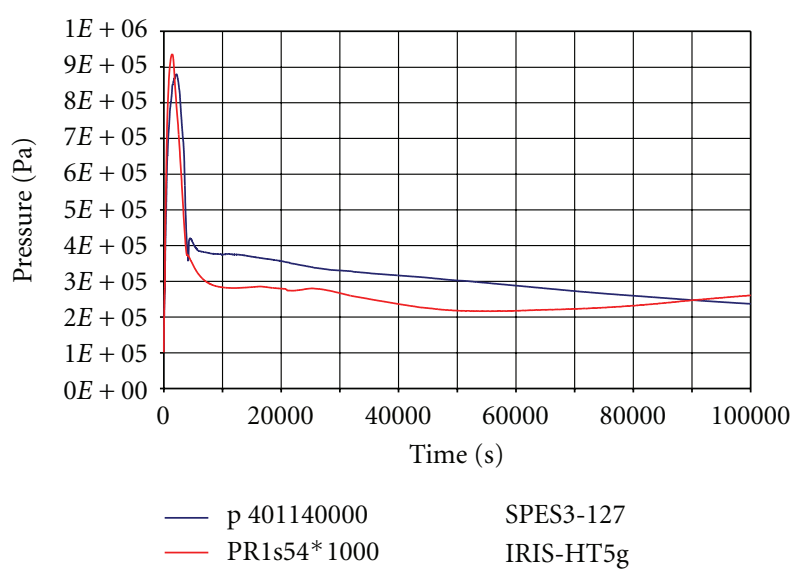

FIgURE 33: SPES3-127 and IRIS-HT5g DW pressure. 

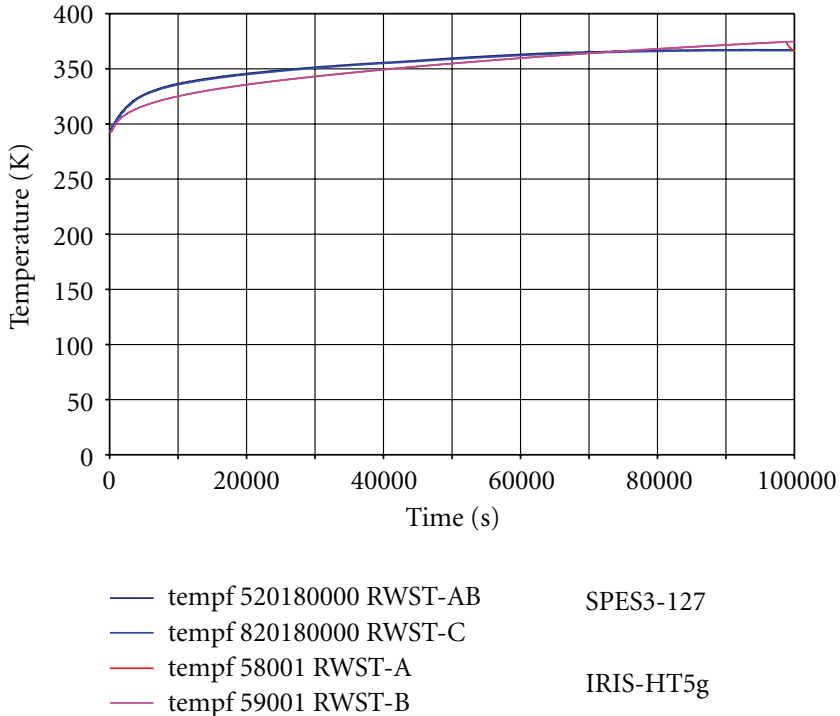

FIgURE 34: SPES3-127 and IRIS-HT5g RWST temperature.



$\begin{array}{ll}\text { - RWST out tot mass } & \text { SPES3-127 } \\ \text { RWST out tot mass } & \text { IRIS-HT5g }\end{array}$

FIgURE 35: SPES3-127 and IRIS-HT5g RWST top integral mass flow.

The SPES3 PSS bottom remodelling was the further attempt to investigate PSS vent pipe emptying at the end of PSS injection into the DW. No important differences were observed. The SPES3-127 results were used to investigate the EHRS heat transfer to RWST, considered the cause of the different containment pressure trend in the long term, where IRIS increased after $50000 \mathrm{~s}$ while SPES3 continued to decrease (Figure 33). RWST temperature in SPES3 did not reach saturation, but established at lower values (Figure 34), due to the direct connection, in the model, of RWST top with the atmosphere control volume, and mass lost through RWST top caused by water solution in dry air with energy removal and temperature limitation (Figure 35).

That phenomenon led to a further modification of the model with the introduction of a discharge pipe at RWST top, limiting the contact surface with air and solving the problem of RWST water temperature that, finally, could
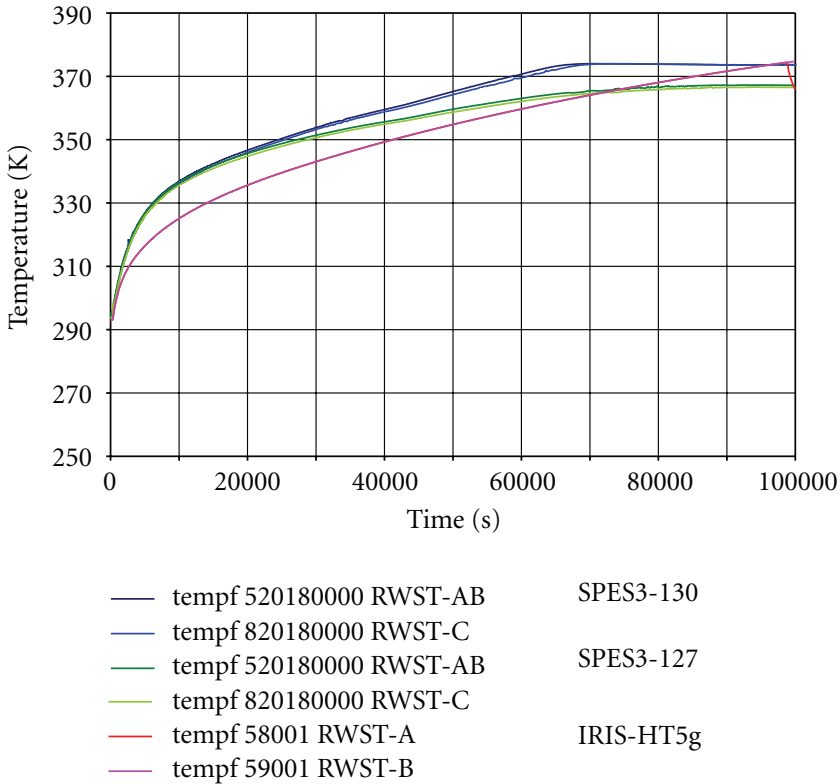

Figure 36: SPES3-130, 127 and IRIS-HT5g RWST temperature.
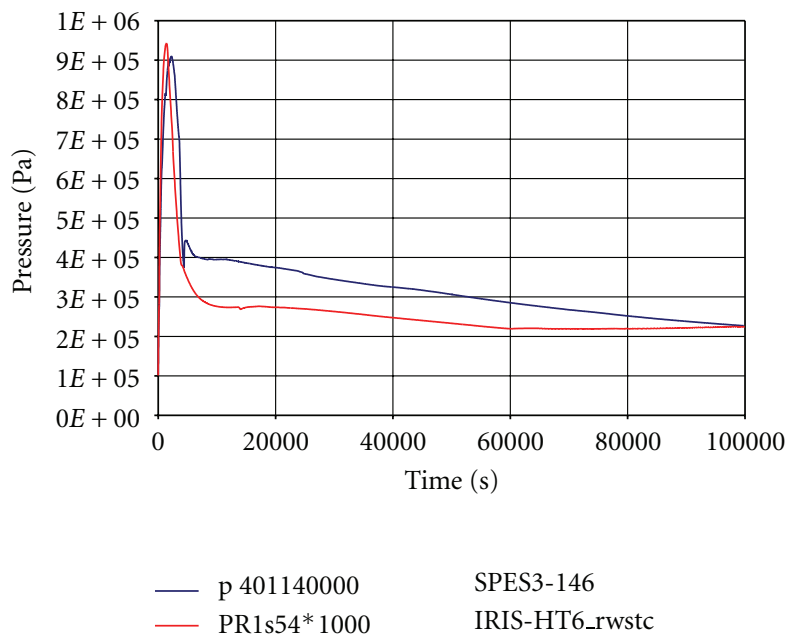

FIGURE 37: SPES3-146 and IRIS-HT6_rwstc DW pressure.



FIgURE 38: SPES3-146 and IRIS-HT6_rwstc PRZ pressure. 


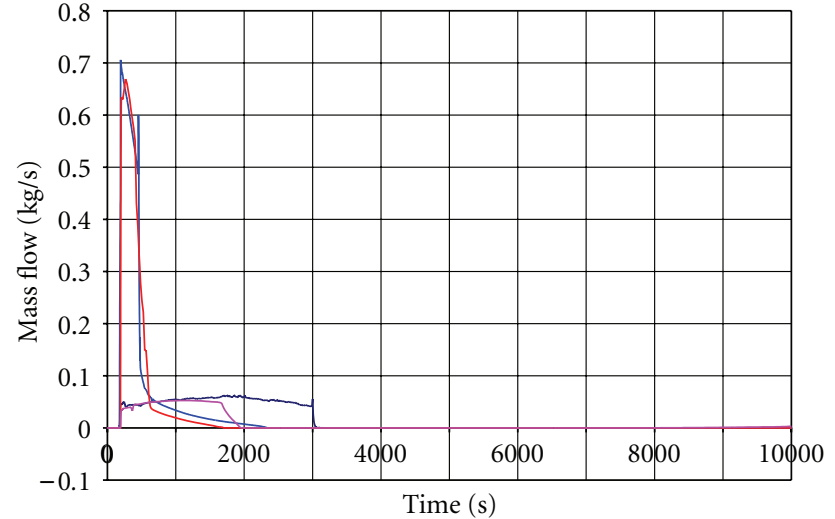

\begin{tabular}{lll} 
mflowj 607000000 EBT-A & SPES3-146 \\
mflowj 627000000 EBT-B & \\
- MFLOWJ 605/100 EBT-A & IRIS-HT6_rwstc \\
\hline & MFLOWJ 625/100 EBT-B &
\end{tabular}

FIGURE 39: SPES3-146 and IRIS-HT6_rwstc EBT injection mass flow (short term).
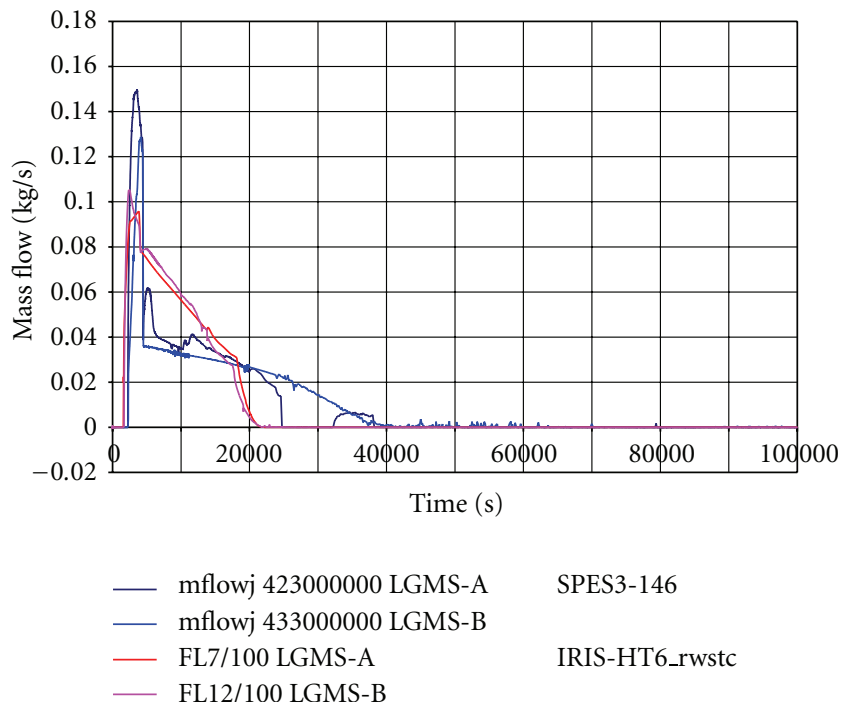

FIGURE 40: SPES3-146 and IRIS-HT6_rwstc LGMS to DVI injection mass flow.

reach saturation (Figure 36). Faster water heat-up in SPES3 showed that EHRS energy transfer to the RWST is greater than IRIS. That led to a series of sensitivity cases on a stand-alone model of EHRS-RWST that led to investigating the differences between the models and finding a common modelling approach based on experimental data on an in-pool heat exchanger and literature values of the heat transfer coefficients [13]. The method provided proper multiplying factors for the HTC to be applied to tube heat structures, condensing and boiling side, in the form of fouling factors [14] and a criterion to set the area of the pool slice containing the heat exchanger. IRIS EHRS-RWST was modified accordingly in the IRIS-HT6_rwstc case. A standalone model was also utilized to calibrate pressure drops in

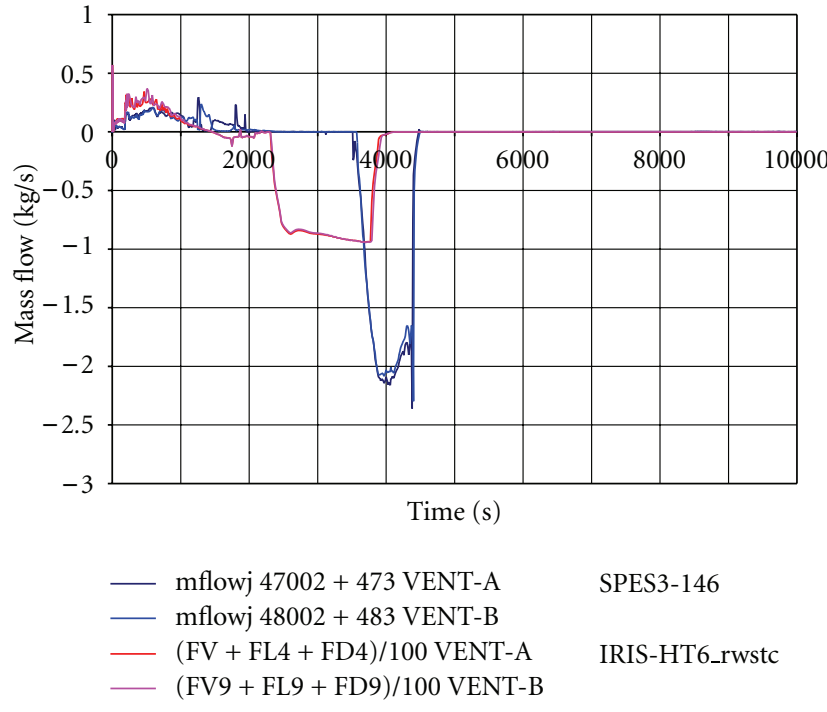

FIGURE 41: SPES3-146 and IRIS-HT6_rwstc PSS to DW injection mass flow (short term).
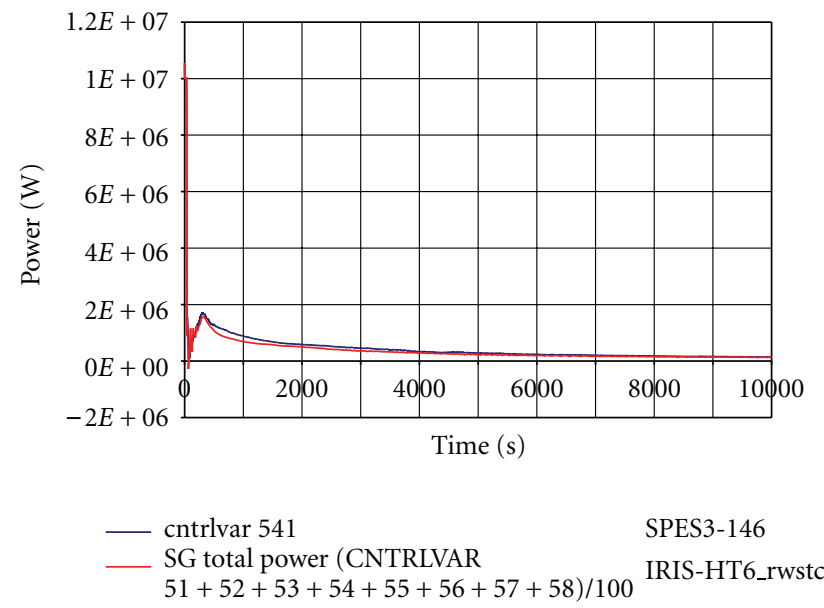

FIGURE 42: SPES3-146 and IRIS-HT6_rwstc SG power (short term).

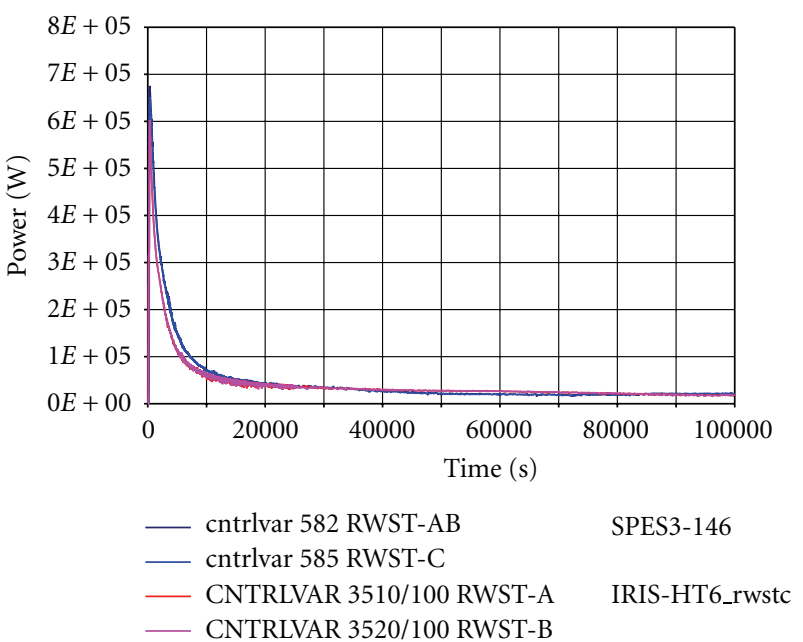

FIgURE 43: SPES3-146 and IRIS-HT6_rwstc RWST power. 


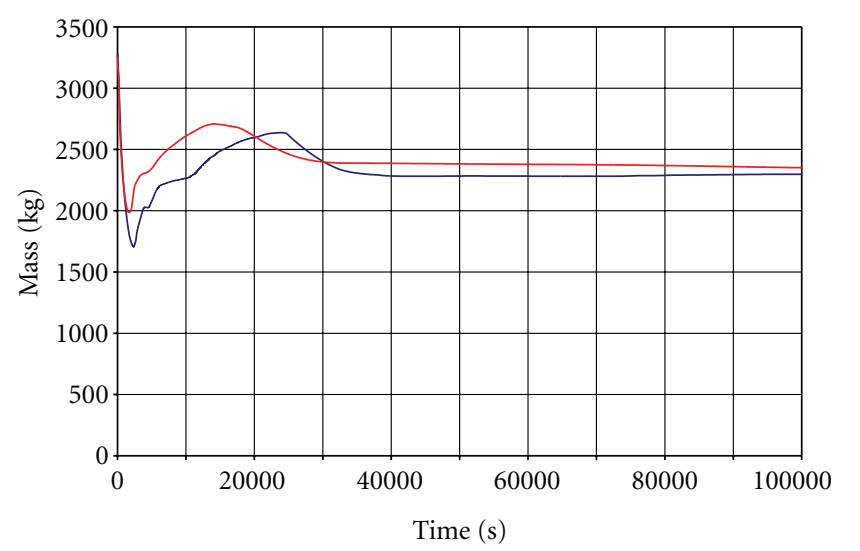

$\begin{array}{ll}\text { - cntrlvar 408 } & \text { SPES3-146 } \\ \text { CNTRLVAR 3219/100 } & \text { IRIS-HT6_rwstc }\end{array}$

FIGURE 44: SPES3-146 and IRIS-HT6_rwstc RV mass.

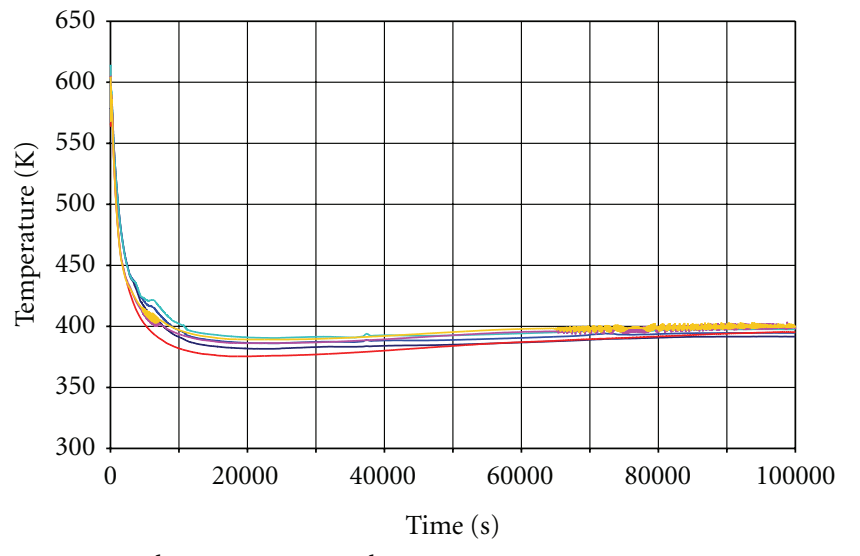

-httemp 110100110 bottom SPES3-146

— httemp 110101110 middle

httemp 110102110 top

- HTTEMP 110100110 bottom

- HTTEMP 110101110 middle

- HTTEMP 110102110 top

FIGURE 45: SPES3-146 and IRIS-HT6_rwstc core heater rod outer surface temperature.

EHRS hot legs and cold legs to properly reproduce the IRIS loops with adjustment to calibrated orifices. Moreover, the need of thermally insulating $4 \%$ of SPES3 HX heat transfer surface was evidenced to compensate for AISI 304 thermal conductivity greater than IRIS Inconel 600.

The SPES3-146 case included all design and model updates previously described and was considered the base case to compare to IRIS-HT6_rwstc. The main quantities of the transient and those that were objective of the SPES3 facility model and design optimization are shown in Figures 37, 38, 39, 40, 41, 42, 43, 44, and 45.

The last IRIS case was successively run to correct some differences, found in RELAP5 and GOTHIC models, about the end elevations of LGMS and ADS stage I lines. Small differences, compared to IRIS-HT6_rwstc results, were found in LGMS flows as well as some changes in ADS stage I flow, after initial discharge. Such differences do not affect or modify the results of the analysis previously described.

The final FSA is planned to be performed on the SPES3146 and IRIS-HT6_rwstcla results.

\section{Conclusions}

The design of the SPES3 facility was finalized thanks to an iterative calculation-design feedback process that allowed to verify the adequacy of containment pressure and reactor vessel mass inventory simulation, objectives of the SBLOCA PIRT for the IRIS reactor [7].

Since the early simulations, efficiency of IRIS safety systems was demonstrated in coping with SBLOCAs. The comparison with the SPES3 results and the early application of the FSA allowed to identify the main causes of discrepancy between the results and to put in evidence specific phenomena particularly affected by simulation choices. The containment heat structures, the heat transfer from EHRS to RWST, and piping pressure drops were found to be the most affecting parameters in matching the IRIS results. The review of the SPES3 design, in accordance to the abovementioned parameter optimization, led to demonstrating that the PIRT identified FoMs are satisfied and that the residual discrepancies can be considered conservative: SPES3 RPV mass lower than IRIS mass and SPES3 heater rod temperatures higher than IRIS ones.

Besides the SPES3 design review, the main outcome of this work is the availability of a set of data suitable for the final FSA application, in progress at the moment, and the quantification of SPES3 facility distortions in IRIS simulation.

The SPES3 facility is under construction at SIET laboratories.

\section{Nomenclature}

ADS: $\quad$ Automatic depressurization system

CIRTEN: Consorzio Interuniversitario per la Ricerca

Tecnologica Nucleare (University Consortium

for Nuclear Technologic Research)

CL: $\quad$ Cold Leg

cntrlvar: (CNTRLVAR) control variable (RELAP5

variable)

CRDM: Control rod drive mechanism

DBA: Design basis accident

DC: Downcomer

DEG: Double ended guillotine

DT: $\quad$ Double train

DVI: Direct vessel injection

DW: Dry well

EBT: $\quad$ Emergency boration tank

EHRS: Emergency heat removal system (EHRS-A, B, C for loops A, B, C)

ENEA: Agenzia Nazionale per le Nuove Tecnologie, l'Energia e lo Sviluppo Economico Sostenibile (Italian National Agency for New Technologies, Energy and Sustainable Economic Development) 
FD: Droplet mass flow rate (GOTHIC variable)

FER: $\quad$ Fakultet Elektrotehnike i Računarstva (Faculty of Electric Engineering and Computing) FL Feed Line

FL: Liquid mass flow rate (GOTHIC variable in the graphs)

FoM: $\quad$ Figure of merit

FSA: $\quad$ Fractional scaling analysis

FV: $\quad$ Gas mass flow rate (GOTHIC variable)

GNEP: Global nuclear energy partnership

GOTHIC: Generation of thermal-hydraulic information for containments

HTC: Heat transfer coefficient

httemp: (HTEMP) heat structure temperature (RELAP5 variable)

HX: Heat exchanger

IRIS: International reactor innovative and secure

ITF: Integral test facility

LGMS: Long-term gravity make-up system

LL: $\quad$ Liquid level (GOTHIC variable)

LOCA: Loss of coolant accident

LP: $\quad$ Lower plenum

LWR: Light water reactor

mflowj: (MFLOWJ) mass flow rate (RELAP5 variable)

NPP: $\quad$ Nuclear power plant

p: $\quad$ (P) Pressure (RELAP5 variable)

PIRT: $\quad$ Phenomena identification and ranking table

PR: $\quad$ Pressure (GOTHIC variable)

PRZ: $\quad$ Pressurizer

PSS: $\quad$ Pressure suppression system

QT: Quench tank

RC: $\quad$ Reactor cavity

RELAP: REactor loss of coolant analysis program

RPV: $\quad$ Reactor pressure vessel

RV: $\quad$ Reactor vessel

RWST: Refueling water storage tank

R\&D: $\quad$ Research and development

SB: $\quad$ Small break

SET: $\quad$ Separate effect tests

SIET: $\quad$ Società Informazioni Esperienze

Termoidrauliche (company for information and experiences on thermal-hydraulics)

SG: $\quad$ Steam generator

SL: $\quad$ Steam line

SMR: $\quad$ Small and medium-sized reactor

SPES: $\quad$ Simulatore pressurizzato per esperienze di sicurezza (pressurized simulator for safety tests)

ST: $\quad$ Single train

tempf: (TEMPF) liquid temperature (RELAP5 variable)

WEC: Westinghouse Electric Company LLC.

\section{References}

[1] M. D. Carelli, L. E. Conway, L. Oriani et al., "The design and safety features of the IRIS reactor," Nuclear Engineering and Design, vol. 230, no. 1-3, pp. 151-167, 2004.

[2] M. D. Carelli, B. Petrović, L. E. Conway et al., "IRIS design overview and status update," in Proceedings of the 13th
International Conference on Nuclear Engineering (ICONE1350442 '05), Beijing, China, May 2005.

[3] B. Petrović, M. D. Carelli, and N. Cavlina, "IRISinternational reactor innovative and secure: progress in development, licensing and deployment activities," in Proceedings of the 6th International Conference on Nuclear Option in Countries with Small and Medium Electricity Grids, Dubrovnik, Croatia, May 2006.

[4] M. D. Carelli, B. Petrović, M. Dzodzo et al., "SPES-3 experimental facility design for IRIS reactor integral testing," in Proceedings of the European Nuclear Conference (ENC '07), Brussels, Belgium, September 2007.

[5] M. Carelli, L. Conway, M. Dzodzo et al., "The SPES3 experimental facility design for the IRIS Reactor simulation," Science and Technology of Nuclear Installations, vol. 2009, Article ID 579430, 12 pages, 2009.

[6] R. Ferri, A. Achilli, C. Congiu et al., "SPES3 facility and IRIS reactor numerical simulations for the SPES3 final design," in Proceedings of the European Nuclear Conference (ENC '10), Barcelona, Spain, May June 2010.

[7] T. K. Larson, F. J. Moody, G. E. Wilson et al., "Iris small break loca phenomena identification and ranking table (PIRT)," Nuclear Engineering and Design, vol. 237, no. 6, pp. 618-626, 2007.

[8] IAEA-TECDOC 1536, "Status of small reactor designs without on-site refuelling (IAEA '07),” 2007.

[9] R. Ferri and C. Congiu, SPES3-IRIS facility nodalization for RELAP5 Mod.3.3 code and steady state qualification. SIET 01 423 RT 08 Rev.0, ENEA FPN-P9LU-017, 2009.

[10] R. Ferri and C. Congiu, SPES3-IRIS facility RELAP5 base case transient analyses for design support. SIET 01489 RT 09 Rev.0., ENEA FPN-P9LU-035, 2009.

[11] R. Ferri and C. Congiu, SPES3-IRIS facility RELAP5 sensitivity analyses of the Lower Break transient for design support. SIET 01499 RT 09 Rev.0., FPN- P9LU-040, 2009.

[12] R. Ferri, SPES3-IRIS facility RELAP5 sensitivity analyses on the containment system for design review. SIET 01526 RT 09 Rev.0., ENEA NNFISS-LP2-017, 2010.

[13] R. Ferri and P. Meloni, Approach for a correct simulation of the SPES3-IRIS Emergency Heat Removal System with the RELAP5/MOD3 Code. SIET 01745 RT 11 Rev.0. Piacenza, Italy, 2011.

[14] RELAP5 code manual. NUREG/CR-5535/Rev.1 Idaho National Engineering Laboratory (USA), 2001. 

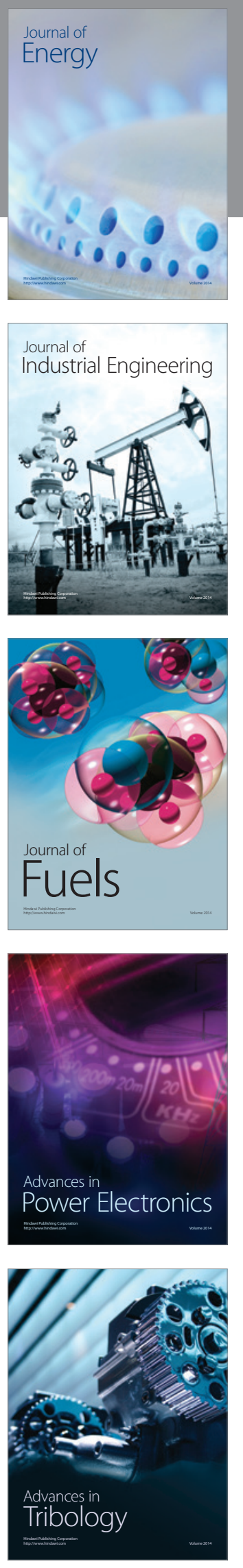
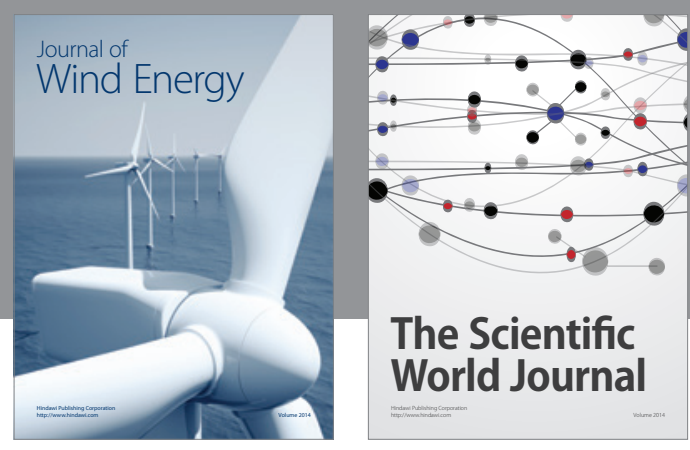

The Scientific World Journal

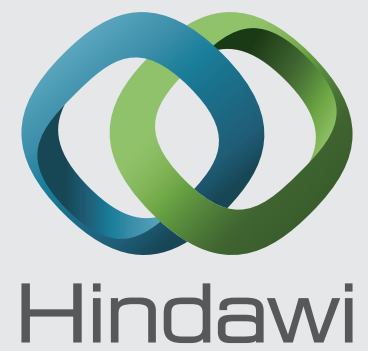

Submit your manuscripts at http://www.hindawi.com
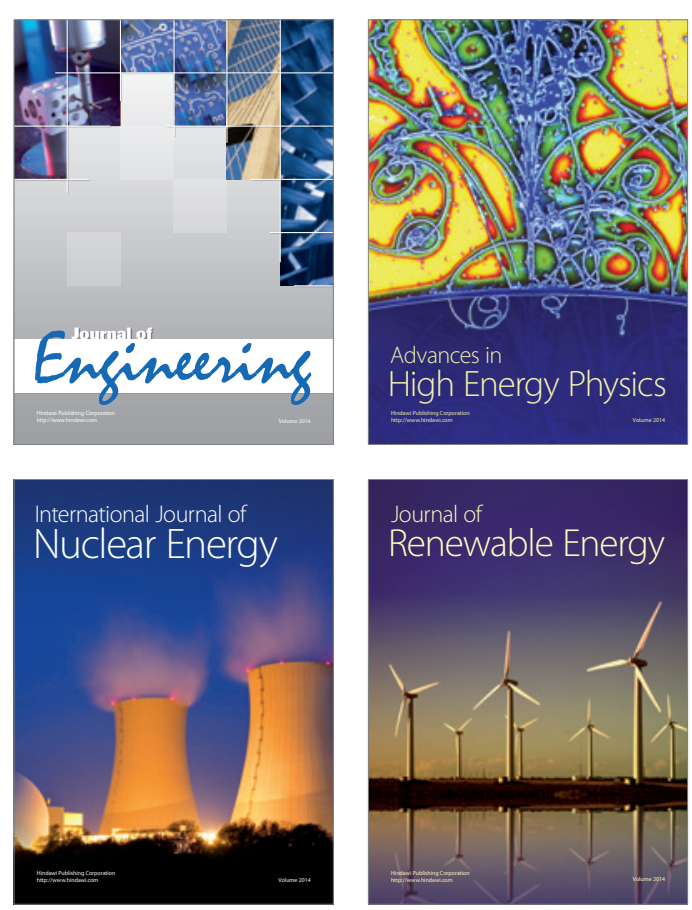

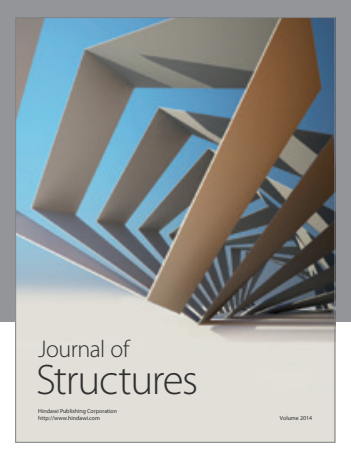

Rotating
Mechinery
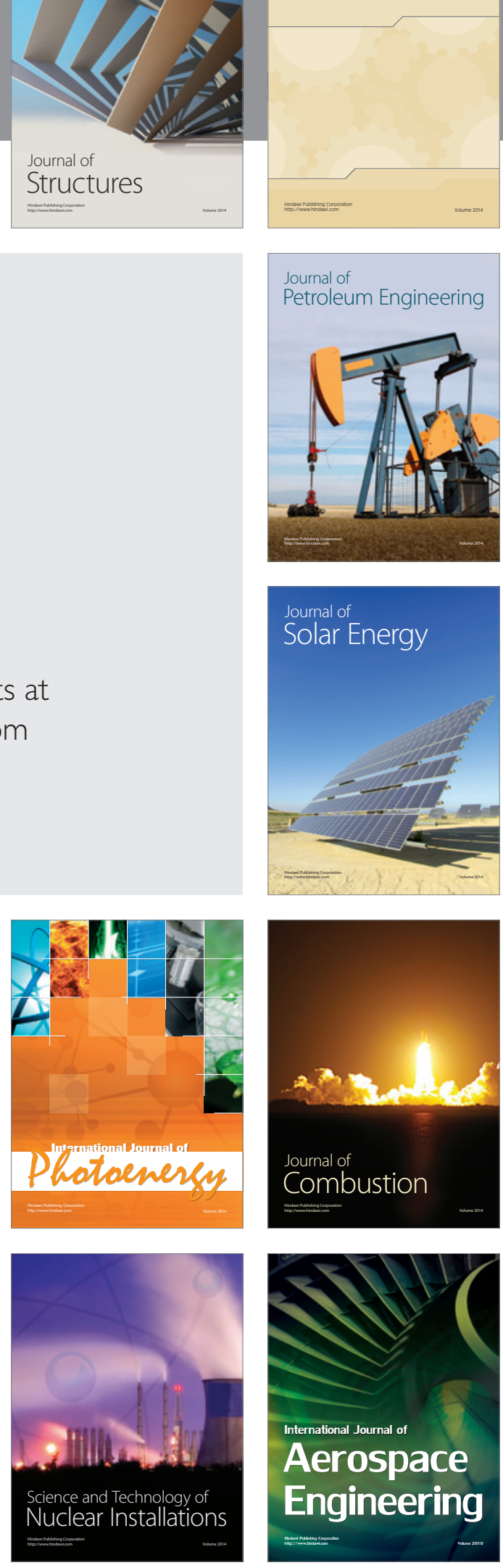